\title{
13th National Congress of the South African Society of Psychiatrists
}

\author{
Champagne Sports Resort, Drakensberg, 20 - 23 September 2004
}

\section{INTEGRATING THE ART AND SCIENCE OF PSYCHIATRY}

Eugene Allers

Private Practice

The history of Psychiatry is presented regarding the development from a dualistic approach to the present systems and constructivist approaches. This is integrated in the psychotherapeutic techniques and principles of modern psychiatry.

The history of the development of biological treatments and the paradigms of the various periods in the development of treatments in Psychiatry is explored.

The biological neurotransmitter systems and the developments of the latest discoveries in the neurotransmitter system are discussed as a system interfaced with the present psychological theories.

The Psycho-Social interventions are integrated with the Psycho-Biological theories, with feedback loops and the influence and interactions of the different systems on one another.

The present theories regarding the Bio-Psycho-Social model is presented.

\section{CHRONIC PAIN AS A PREDICTOR OF OUTCOME IN AN INPATIENT PSYCHIATRIC POPULATION}

Eugene Allers and Gerhard Grundling

Private Practice

\section{METHOD}

Data of all inpatients admitted to the Springs Parkland Clinic psychiatric inpatient unit were collected for a period of 6 months from the 01 January 2002 until 30 June 2002. The population is investigated and the data is analysed through comparing the patients with chronic pain who abuse opiates, defined through a positive opiate urine level at the time of admission and patients with chronic pain who admit to analgesic abuse but negative urine opiate levels, and patients with chronic pain and no analgesic abuse and patients who do not complain of pain or analgesic abuse.

The Zung scores and the vital sign response of the patients are analysed as a measure of response to inpatient treatment.

\section{RESULTS}

183 Patients were admitted to the psychiatric inpatient unit. 4 patients were admitted twice and 1 patient 3 times, a total of 189 admissions.

The results are discussed regarding the relevance of pain and analgesic abuse and the response to treatment.

\section{RECENT ADVANCES IN SOCIAL PHOBIA}

Christer Allgulander

Associate Professor, Karolinska Institutet, Stockholm, Sweden

The aim is to provide an overview of recent published research into social phobia (SAD for Social Anxiety Disorder) that is relevant to future clinical studies. Since 1984 there are 1357 PubMed citations. SAD is now recognized as a public health issue with a 1-year prevalence of 2-3 per cent, although it remains underdiagnosed. Screening instruments have been developed. Evidence-based treatment guidelines are established based on cognitive behavioural approaches (CBT) and serotonergic medications as drugs of choice.

Twin studies document the heritability of fear of negative evaluation. Children with behavioral inhibition at age 2 displayed increased amygdala response to unfamiliar faces at age 22. Taking a test in front of an audience triggered a cortisol response indicative of increased HPA axis reactivity in SAD subjects.

Neuroimaging studies have employed anxiety provocation to document amygdala as the focus of response to perceived social threats. This response is attenuated by CBT or serotonergic medication. The serotonin reuptake transporter (SERT) became highly occupied at therapeutic doses of paroxetine in patients with SAD.
Healthy women recognize happy and fearful faces faster and more accurately when administered citalopram iv. Patients with SAD avoided looking at the eyes of faces in such an experiment. The avoidance of eye contact was also documented in videotape recordings of SAD subjects while conversing. Although shyness is perceived as a typical SAD feature, 82 per cent of shy subjects did not meet with the SAD diagnostic criteria.

A substantial portion of SAD subjects suffer from hyperhidrosis, and subjects with paruresis or cervical dystonia frequently suffer from SAD. Elective mutism may be considered an early variant of SAD. Alcohol abuse was found to be common in SAD subjects, although one study found alcohol to be no more a social anxiolytic than placebo. Women with SAD more often lacked a sex partner, and more often reported impairment in arousal and satisfaction, and men with SAD more often paid for sex.

Delienating primary SAD from innocuous forms of social anxiety remains an issue.

Recent treatment studies include SSRIs, SNRIs, pregabalin, and virtual reality.

\section{CLINICAL MANAGEMENT OF PATIENTS WITH ANXIETY} DISORDERS

Christer Allgulander

Associate Professor, Karolinska Institutet, Stockholm, Sweden

The neurobiology of anxiety and affective disorders appears to be shared, and patients with primary anxiety disorders are at increased risk of developing secondary depressive episodes. Frequently, these disorders are found within the same family, indicating a shared diathesis.

The SNRIs and SSRIs are now established as the treatment of choice in major depression and anxiety disorders. In controlled studies the response rate is about 70 per cent, and with maintenance treatment remission can be seen in a

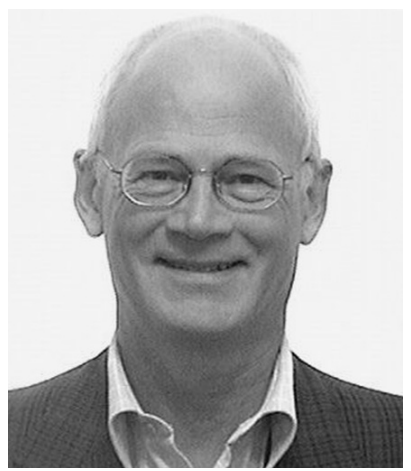
majority of the cases. There are no known irreversible adverse effects, yet sexual effects and discontinuation symptoms are to be expected. In children, caution must be paid to increased irritability and suicidal ideation with some of these medications.

The increased utilization of these medications has been parallelled with reductions in suicide rate in several countries. In Sweden the number of suicides decreased with 31 per cent in the last decade, and 6 per cent of primary care patients are on maintenance treatment with SSRIs or SNRIs. European studies show anxiety and depressive disorders to be the most common in primary care next to musculoskeletal conditions.

Emerging research shows benefit of antidepressive and anxiolytic treatment in patients with concurrent stroke, myocardial infarction, and diabetes in whom this treatment reduces the risk of somatic complications and increases the likelihood of successful rehabilitation. Alcohol dependence can sometimes be prevented and treated by identifying subjects with comorbid depression and anxiety who self-medicate with alcohol.

Studies show that it is cost-effective to empower nurses to take charge of caring för subjects that doctors have targeted for treatment of anxiety and depression. Treatment adherence can be enhanced by teaching the patient elementary coping skills by means of individual or group counselling. The internet provides access to support groups, to educational websites, and to online cognitive skills training. Yet, a minority of affected persons in the community receive effective treatments for these disorders.

Clinical research units in Europe and in South Africa are now working together to further the understanding of the genetics, epidemiology, psychotherapies and pharmacotherapies of mood and anxiety disorders. 
DO ELEPHANTS SUFFER FROM SCHIZOPHRENIA? (OR DO THE SCHIZOPHRENIAS REPRESENT A DISORDER OF SELF CONSCIOUSNESS?) A SOUTHERN AFRICAN PERSPECTIVE

Sean Exner Baumann

Department of Psychiatry and Mental Health, University of Cape Town

There are limitations to the validity and usefulness of the concept of schizophrenia. These limitations have important treatment implications. A re-evaluation of the phenomenology of the disorder, and in particular the formation of delusions, provides a potentially useful heuristic framework. A disturbance of the experience of self, and of the self in relation t the external world, may underpin the phenomenology of schizophrenia. Putative biolog ical substrates ae described, and an integrative model is proposed, whereby higher centres, or mind, strive to modulate lower biological events, experienced as anomalous, in order to retrieve a meaningful homeostasis. These distorted representations form the characteristic symptoms of schizophrenia. Analogies are drawn with current strategies for managing chronic pain. Differences in the value accorded to the self across cultures, and the variations in outcome corresponding to these differences, are proposed as tentative evidence, and indicate a need for a paradigm shift in the philosophy of treatment of the disorder.

\section{LONG TERM MAINTENANCE TREATMENT OF BIPOLAR} DISORDER: PREVENTING RELAPSE

Charles L. Bowden

University of Texas Health Science Center, San Antonio

Maintenance treatment of bipolar disorders should be illness focused, not episode-focused. Most patients with bipolar disorder have minor symptoms between episodes, even during sustained periods of remission. The cornerstone of maintenance treatment is effectively using a recently expanded group of drugs that, along or in combination, provide a good chance of prophylaxis against new episodes; maintaining subthreshold symptomtology at levels compatible with good function; and yielding tolerability that neither impairs function, nor predisposes patients to poor and valproate have the best evidence for long term efficacy as primary mood stabilizers. Two randomized maintenance comparisons between valproate and lithium indicate relatively equivalent efficacy between the two drugs, with better tolerability for valproate than for lithium, including fewer early discontinuations. Both valproate and lithium primarily control manic symptomatology, although some maintenance phase control of depression is suggested by some studies, especially for valproate. Valproate and olanzapine were equivalently efficacious in a maintenance study, with valproate better tolerated. Lamotrigine has been demonstrated efficacious in reducing depressive symptomatology during maintenance treatment of bipolar I and II patients for periods up to 18 months. Atypical antipsychotics appear to further control manic relapse when added to either lithium or valproate, although the benefit seems limited to a small subset of patients. Combinations of lithium and valporate, and lamotrigine and either valproate or lithium, appear to be safe regimens, and to provide complementary benefit in some patients, although studies to date are relatively small, and often naturalistic.

\section{PREDICTORS OF RESPONSE TO TREATMENTS FOR BIPOLAR DISORDER}

Charles L. Bowden

University of Texas Health Science Center, San Antonio

Predictor of response in acutely manic patients have largely been linked to subtypes, with mixed mania associated with a more efficacious response to valproate than to lithium. More illness episodes are predictive of lesser efficacy of lithium compared with valproate. Several indices of greater illness severity generally predict less efficacious response to all established antimanic drugs. Euphoric mania is associated with favorable outcomes with both lithium and valproate. Irritability was associated with efficacious response to valproate, but not to lithium, or placebo. Depressive components to mania have generally predicted poor response to anti-manic agents Bipolar depressed patients who responded to lamotrigine had differentially greater improvement on psychomotor retardation and cognitive symptoms of depression.

Predictors of response in maintenance are both more complex, and less well studied. For valproate and for lamotrigine, and for olanzapine in combination with lithium or valproate, acute response was associated with effective maintenance outcomes. Conversely, acute response to lithium did not predict response or non-response during maintenance treatment. Mixed manic features have been associated with less effective maintenance response to olanzapine and lamotrigine. For lithium and valproate, mixed mania did not predict maintenance outcome, whereas patients with initial euphoric mania had more effective maintenance outcomes when randomized to valproate than to placebo or lithium. As in acute mania, more illness episodes predicted less effective maintenance response to lithium. Some predictors of outcomes do not appear specific to a particular regimen. Obesity predicted poor outcomes in maintenance therapy for principally lithium treatment, but other treatments employed as well.

\section{AIDS/HIV KNOWLEDGE AND HIGH RISK BEHAVIOUR: A GEO- GRAPHICAL COMPARISON IN A SCHIZOPHRENIA POPULATION}

Buckley P, Van Vuuren S, Koen L, Muller JE, Seller C, Lategan H, Niehaus DJH

Department of Psychiatry, University of Stellenbosch

\section{BACKGROUND}

International studies have shown that schizophrenia patients exhibit lower levels of HIV/AIDS knowledge. This lack of knowledge has serious implications for the prevention of the spread of HIV/AIDS. Given the high incidence of HIV/AIDS in Sub-Saharan Africa, it would be imperative to replicate these studies in Southern African populations. The aim of this study was twofold to assess the levels of knowledge in South African schizophrenia patients from a rural area and to compare these findings with studies in urban areas.

\section{METHODS}

Schizophrenic patients from rural KwaZulu-Natal were assessed in terms the AIDS Risk Behaviour (ARB) and AIDS Knowledge questionnaires Statistical analysis was performed using the SPSS software package.

\section{RESULTS}

Forty-nine patients were recruited. A quarter of these were sexually active and $8.1 \%$ had two or more sexual partners. The group underestimated the risks associated with heterosexual intimacy, but was aware of mother-baby transmission.

\section{CONCLUSION}

This study forms part of an ongoing effort focusing specifically on HIV/AIDS knowledge in the South African schizophrenia population and confirmed an overall knowledge deficit similar to previous findings in other geographical areas within South Africa.

\section{DOES MARIJUANA MAKE YOU GO MAD?}

David J Castle

Mental Health Research Institute and University of Melbourne, Australia

Cannabis sativa (marijuana) has been used by humans for centuries, largely for its psychological effects. It has been known for many years that people who suffer psychotic illness are far more likely to consume cannabis than the general population, and there has been much dispute about the reasons for this. Unfortunately, until recently there was relatively little data available to inform this debate. The situation has changed greatly over the last decade with the publication of new basic and clinical studies. Therefore, this presentation will provide an overview of the psychiatry and neurobiology of cannabis, with particular emphasis on psychotic disorders. It will review not only of the direct psychomimetic properties of cannabis, but also the impact consumption has on the course of evolving and established mental illnesses such as schizophrenia. It will also address two very contentious issues, namely whether a discrete 'cannabis psychosis' exists, and whether cannabis can actually cause schizophrenia. 


\section{UNDERSTANDING AND MANAGEMENT OF TREATMENT RESISTANT SCHIZOPHRENIA}

David J Castle

Mental Health Research Institute and University of Melbourne, Australia

Despite advances in the pharmacological treatment of schizophrenia and related disorders, a proportion of people with these conditions continue to have sub-optimal outcomes. It is important for the field to appreciate that schizophrenia is a heterogeneous condition with disparate outcomes. We also need to have a broader understanding of 'outcomes', and not focus solely on psychotic symptoms per se. This presentation looks at how a broad range of outcomes (including positive, negative and co-morbid symptoms, cognition, substance misuse, relationships, and vocation) can be addressed, using both psycho-social and pharmacological approaches. It is suggested that a holistic approach incorporating effective elements of proven treat ments, will provide the best opportunity for people with schizophrenia to achieve optimal outcomes across disparate domains of functioning.

\section{WORKSHOP ON RESEARCH AND PUBLISHING}

David J Castle

This workshop will provide an interactive opportunity for trainees and junior consultants to look at practical aspects of psychiatric research. Particular emphasis will be placed on the 'how' of research in psychiatric clinical settings, including a step-wise approach to tackling a particular research question. Participants are encouraged to bring research ideas (however ill-formulated!) for discussion and brainstorming by the group. The second part of the workshop will more specifically address publishing in psychiatry, and will again provide a step-wise approach to writing an article for a scientific journal.

\section{FROM VICTIM TO VICTOR: WITHOUT A SELF-HELP BOOK}

Coetzee, Beatrix Jacqueline

Clinical Psychologist; Riverview Manor, Underberg, South Africa

\section{Introduction}

Use of relaxation and visualization in addressing feelings of guilt, as demonstrated in heterogenous inpatient treatment group.

\section{Research Hypotheses}

(VICTIM TO VICTOR! principle)

Guided RE-EXPERIENCING of "inaccessible" and deep seated feelings of GUILT and SHAME as presented in hospitalized individuals, (alcoholics, addicts, depressives, eating disorders)(STRICTLY NO INDIVIDUALS WITH PSYCHOTIC FEATURES) that are unable to significantly progress in therapy, despite therapeutic efforts poses to be a constructive and healing experience within a contained group context.

\section{Qualitative Research Design}

In 14 years of experience counselling substance abusers, alcoholics, depressives, eating disorders and the likes it came to the light that many of the above individuals get "stuck" in their recovery by blaming everyone and everything around them for their problems, i.e., a VICTIM CONCIOUSNESS. There is often a reluctance to take responsibility for their part in their illnesses. Blaming becomes a mode of operating, thus MANIPULATION sets in as an only way of relating. Under all of this a process of unseen GUILT slowly builds a protective and effective shield. (This will be demonstrated in detail on a flip chart with a voluntary group at the workshop). In order to break this cycle the individual needs to be made aware of these harmful patterns in a non-threatening manner. They further need to be GENTLY guided (preferably verbally) to places and events where they have hurt, harmed, destroyed disappointed, etc., significant others. This is a very skilful exercise, however easy it might sound, because especially the addicted individual is extremely sensitive to your sincerity. ONE CAN RATHER BE HARSH, THAN SWEET, AS LONG AS YOU ARE SINCERE AND HONEST TO THE "bone".

This particular qualitative study design is done on grounds of years of IN SERVICE clinical observation.

SPECIFIC RESPONSES WILL BE POINTED OUT ON THE VIDEO MATERIAL.

Feelings of guilt, shame have proven in my 14 yrs of clinical experience to emotionally paralyze many any individual attempting to recover from various problems.

In view of the above I have developed a very simple yet effective technique to assist the person to experience the shame and guilt on an emotional level, as opposed to an intellectual level and thus experience a difficult, yet cathar- tic and purifying Feeling.

As mentioned the technique consists of a relaxation exercise, visualization and debriefing.

Due to the emotive intensity of this therapy, it is advisable that only those interested and trained should be allowed to practice this technique, however simple it may seem.

NB: insufficient, unprofessional and inadequate debriefing may have dangerous consequences for the individual exposed to the mentioned group. Other than doing my presentation, I endeavour to do a brief practical demonstration with a few volunteers, to present video material and to give practical guidelines.

\section{THE EVALUATION OF THE GENDER DYSPHORIC PATIENT}

Franco Colin

Private Practice, Pretoria

Gender dysphoria is not a common presentation to the average psychiatrist's practice. It does however present a vexing problem which often leaves the psychiatrist with a sense of not knowing what to do or how to approach the problem. This lecture is aimed at describing the approach to the diagnosis and understanding of gender dysphoria in its various forms. It aims to describe briefly the basic approaches to further mangement and referral.

\section{DISSOCIATION: A SOUTH AFRICAN MODEL}

Dikobe AM, Mataboge CK, Motlana LM, Sokudela BF, Krüger C Weskoppies Hospital, Pretoria

\section{Background:}

We had found that a direct application of the DSM model of dissociation in our professional context was problematic. Translation did not work, because the equivalent words sometimes did not exist in our local languages (e.g. "unreal"), and because the equivalent concepts sometimes did not appear to fit our context. We set out to explore why the global medical (DSM) mode did not fit our context, and to elaborate an urban South African explanatory social model of dissociation.

Methods:

We drew on our cultural heritage, which includes a mixture of, i.a., Sesotho, Setswana, Zulu, Xhosa, and Afrikaans urban South African traditions, on shared global urban cultural elements, and on shared experience in the fields of medicine and psychiatry, as women. We examined the phenomenon of dissociation in terms of our worldviews, our perspectives on mental illness and on spirituality, and our appreciation of healing.

\section{Results:}

We view dissociation not as an intrapsychic process only, but as having interpersonal / social / collective dimensions too. Dissociation is a norma information-processing tool that filters out different sets of information. It serves to maintain a coherent sense of self in society. Traumatic events or conflicting values (within one person or between people) represent challenges to individual or collective information processing, and may precipitate dissociation. Dissociation in our South African context is often socially and culturally sanctioned, e.g., in religious and spiritual ceremonies. Thus relatively few instances of dissociation are explained in terms of dissociative disorders.

Conclusions:

The global medical (DSM) model of dissociation would need to be expanded by an explanatory social dimension to fit our South African context. We should develop more local terminology relating to dissociation to help in studying dissociation further in future and to enrich psychiatric practice in South Africa.

DESIGNATED SMOKING ROOMS... AND OTHER "SECRET SINS" OF PSYCHIATRY: TOBACCO CESSATION APPROACHES IN THE SEVERELY MENTALLY ILL.

Charl Els

Department of Psychiatry, University of Alberta Hospital, Canada

Tobacco dependence is a global pandemic. Tobacco is the only legal consumer product that will eventually kill half of its regular users when the product is used exactly as intended. The prevalence of tobacco smoking in the schizophrenia population is estimated at up to $\sim 90 \%$, compared to the roughly $21 \%$ of the general Canadian population. The chemically dependen 
population, the mentally ill, those with low educational levels, those living in low social-economic conditions, and blue-collar workers are disproportionately burdened by this addictive illness. Despite the astounding prevalence and devastating health impact in the mentally ill, several barriers to treatment exist, including the availability of designated smoking rooms in psychiatric facilities, inequality in the parity of coverage of treatment, physician factors, and other systemic barriers: The so-called "Secret Sins of Psychiatry". The public health model's paradigm will be used to demonstrate specific opportunities and challenges in tobacco control in the mentally ill, namely (1). Cessation (pharmacotherapy and psychosocial interventions), (2). Denormalization, and (3). Policy changes. Several major health authorities in Alberta and elsewhere in Canada have successfully introduced smoke-free psychiatric facilities, with the gradual abolishment of smoking rooms in these hospitals. The role of legislation and its expected impact on designated smoking rooms will also be briefly discussed as part of a comprehensive tobacco control strategy in mental health settings.

\section{DUAL DIAGNOSIS: IMPLICATIONS FOR TREATMENT AND PROGNOSIS}

Charl Els

Department of Psychiatry, University of Alberta Hospital, Canada

Substance abuse is the most common comorbidity among patients with serious mental illness, resulting in poor outcomes and increased health care spending. The use of illicit drugs, alcohol, and tobacco by the severely mentally ill individual adversely affects hospitalization rates, treatment adherence, housing stability, risk for violence, and leads to increased mortality rates and potential years of life lost. Substance abuse in schizophrenia presents complex issues for psychiatrists and other mental health professionals, who often find themselves illequipped to deal with this difficult-to-treat subpopulation, especially in a sequential or parallel treatment system. This session provides a brief overview of the scope of the problem, highlighting the current direction taken in developing an integrated treatment approach in Alberta, Canada. The session will also include the main categories of drugs abused, with emphasis on practical management strategies to optimize treatment outcomes.

\section{BODY WEIGHT, GLUCOSE METABOLISM AND THE NEW GEN-} ERATION ANTIPSYCHOTICS

Robin Emsley

Department of Psychiatry, University of Stellenbosch

\section{Background}

The new generation antipsychotics have substantially changed the way we treat patients with psychotic disorders. Their broader spectrum of efficacy and relatively favourable tolerability profile offer patients a better chance of positive outcome. However, attention has now shifted to a new set of sideeffects, particularly weight gain and its metabolic consequences. Weight gain is highly distressing to patients, and may reduce treatment adherence. It is also related to poorer quality of life and decreased well-being and vitality. Of greatest concern however, is the risk of progression to obesity-related medical conditions such as type 2 diabetes and cardiovascular disease.

\section{Methods}

This presentation reviews the literature on antipsychotics, weight gain and glucose metabolism.

\section{Results}

The so-called metabolic syndrome, characterized by excessive visceral fat, impaired glucose tolerance, dyslipidaemia, and hypertension occurs with increased frequency in patients with schizophrenia. This is the case even before antipsychotic treatment is administered. The reasons for this are not clear, although factors such as life style, poor diet and lack of exercise may play a role. Antipsychotics can cause hyperglycaemia, exacerbation of existing diabetes, new-onset type 2 diabetes and even diabetic ketoacidosis Various mechanisms may be operant. The risk is greatest for low-potency conventional antipsychotics and the new generation antipsychotics, particularly clozapine and olanzapine.

\section{Conclusions}

The topic of antipsychotic-induced weight-gain and its relationship to glucose metabolism is understudied. However, available evidence points to widespread disorders of glucose metabolism in patients treated with antipsychotics, with consequent increased risk of variousmedical conditions. Regular monitoring of weight, blood glucose and lipid profile for patients on antipsychotics is strongly recommended.

NEUROLOGICAL ABNORMALITIES IN FIRST EPISODE SCHIZOPHRENIA: TEMPORAL STABILITY AND CLINICAL AND OUTCOME CORRELATES.

Robin Emsley, H Jadri Turner, Piet P Oosthuizen, Jonathan Carr

Departments of Psychiatry and Neurology, Faculty of Health Sciences, University of Stellenbosch

\section{BACKGROUND}

Subtle neurological abnormalities are found more frequently in patients with schizophrenia than in healthy controls and other psychotic disorders. The status of these signs is not clear, and findings have been inconsistent. This study assessed the temporal stability of neurological abnormalities in subjects with first-episode schizophrenia over the course of 12 months. We also examined their relationships with psychiatric symptoms, medication effects and treatment outcome.

\section{METHODS}

The sample comprised 66 largely medication-naÔve subjects who were treated according to a fixed protocol. We performed a factor analysis of the Neurological Evaluation Scale (NES) items, and relationships between the NES factors and various clinical and outcome measures were explored.

\section{RESULTS}

Five NES factors were identified, explaining $68.4 \%$ of the variance. While the NES total scores did not change significantly over time, poor performance on motor sequencing tests was related to longer duration of untreated psychosis, and improved as psychiatric symptoms resolved. Rapid alternating movements worsened over time, perhaps due to the side-effects of antipsychotic medication. The most interesting finding was that high scores on the motor sequencing factor predicted the emergence of persistent dyskinesia at 18, 21 and 24 months $(\mathrm{r}=0.67 ; \mathrm{p}=0.02)$.

\section{CONCLUSION}

Two NES factors are replicable across samples, and have potential relevance for the further exploration of the pathogenesis of schizophrenia, as well as possible clinical applications. Impairment on the repetitive motor factor may be progressive while psychotic symptoms remain untreated, and improve as the symptoms resolve with treatment. Also, impairment on this factor may be an important predictor of vulnerability to TD. The cognitive/perceptual or attentional factor appears to be stable over time, diagnosis specific, and possibly reflects a stable characteristic of schizophrenia with specific neuroanatomical underpinnings.

\section{MYTHOLOGY OF DEPRESSIVE ILLNESSES AMONG AFRICANS}

Senathi Fisha

Clinical Psychologist in Private Practice and CEO, Banabaka Care Institute

\section{EVOLUTION}

In 2000 the World Health Organization (WHO) reported that depressive illnesses are the commonest mental disorders, the fastest spreading around the world and the most severe illnesses afflicting adults. Furthermore, reports indicated that depression would be the third killer in the world by 2020. and that for every five people suffering from depression and seeing a medical doctor, one is misdiagnosed.

Studies done in the past regarding depression in Africa are limited and did not clarify wether depression exist in this community or not and wether depression is the same as found in Western countries. These have caused delays in the progress of understanding, diagnosing and control of depression in Africa. Unmodified Western approaches and theories have been used without checking their relevance to the African context.

\section{METHODOLOGY}

The aim of the study was to clarify the myth of whether depression exists amongst the African communities or not.

Instruments

Three psychological instruments namely, BDI, Rorschach and MMPI and a Structured Psychological Questionnaire were administered to depressed in patients. 
Participants

One hundred and sixty two in patients of between 18 and 50 years took part in the study.

Methodology

All instruments were administered on their first day of admission after the psychiatrist has diagnosed them with DSM IV.

\section{RESULTS}

Results showed that most Africans especially in urban areas show psychological sophistication and able to express depressive symptoms accurately.

\section{SUBSTANCE USE AND HIGH SCHOOL DROPOUT}

Alan J. Flisher ${ }^{1}$, Lorraine Townsend ${ }^{1}$, Perpetual Chikobvu ${ }^{1}$, Carl Lombard ${ }^{2}$ \& Gary King ${ }^{2}$

Department of Psychiatry and Mental Health, University of Cape Town, Biostatistics Unit, South African Medical Research Council ${ }^{2}$ and Department of Biobehavioral Health, The Pennsylvania State University ${ }^{3}$

\section{BACKGROUND}

This paper examines the association between tobacco, alcohol and illegal drug use and school dropout by high school students in Cape Town, South Africa.

\section{METHODS}

A multistage cluster sampling approach yielded a sample of 1457 students in grade 8 at 39 high schools in Cape Town who completed self-administered questionnaire in 1997. The students were followed up in 1999 (Time 2) and 2001 (Time 3). All student were allocated to one of two groups according to whether they had dropped out or not. We conducted multiple logistic regression analyses of dropout status at Time 3 on substance use and selected potential confounders such as demographic factors (gender and age), family-related factors (being raised by both, one or neither biological parent), socio-economic background, and school-related factors (absenteeism and repeating grade/s). Results were presented as relative risk ratios, which took account of the clustering effect.

\section{RESULTS}

At Time 3, 809 (56.26\%) had dropped out of school and 19 were lost to follow-up. Past month cigarette use among Coloured (RR: 1.87; 95\% CI: 1.09 3.20 ) and White (RR: 1.92; 95\% CI:1.06 - 3.49) students, and having ever used illegal drugs among White students (RR: 5.77; 95\% CI: 2.44 - 13.63) were significantly associated with drop out. None of the substance use measures predicted dropout among Black students.

\section{CONCLUSIONS}

Dropout rates were high, but (unlike international results) substance use had a limited influence on dropout. Further research is underway to identify other factors that predict drop out.

\section{PSYCHOSIS AND PSYCHOTIC DISORDERS}

Gangat, AE

Department of Psychiatry, Nelson R Mandela School of Medicine, University of KwaZulu-Natal

There are several problems in defining, classifying and diagnosing psychotic disorders. Hence there are numerous classification systems in different parts of the world, including the ICD and DSM systems.

There is a lack of clarity in defining, associated terms such as psychosis and psychotic symptoms/features. Differences exist also in the domain of duration of symptoms and counting of symptoms.

This discussion paper explores these problems and makes suggestions towards clarifying these issues.

\section{A CULTURE-SENSITIVE APPROACH TO COUNSELLING A COM- MUNITY WITH PSYCHOLOGICAL TRAUMA FOLLOWING A TRAIN DISASTER}

Goba, Thuthukile

Chief Medical Director, Global Research and Medical Network

Mkize DL

Head Department of Psychiatry, Nelson R Mandela school of Medicine, Faculty of Health Sciences. University of KwaZulu-Natal

\section{BACKGROUND:}

Major accidents are often associated with lasting psychological trauma manifesting at different intervals during the healing process and even years after the incident. There have been reports of symptoms persisting for decades after the injury and also of first presentation several years after the incident which makes the connection even more difficult for the survivor or a clinician who is not aware of that incident in their client's life.

Trauma counseling has been accepted as a useful tool in addressing these sequelae as well as rehabilitation and prevention of further morbidity. I would appear that a culture sensitive approach for specific groups would facilitate healing through familiar contexts.

Following the train accident in Stanger in February 2002 which claimed 26 lives of mostly school children and left more that 120 survivors with varying levels of injury, an intensive culture-sensitive counseling and intervention program was implemented at a primary health care level by a group of concerned health care workers. This was done to assist the survivors and the bereaved to learn positive coping skills as well as to identify and treat those who had developed adverse psychological symptoms.

\section{METHODS:}

A group of the community members affected by this accident including survivors of the crash as well as families of the deceased was identified. The intervention program included individual and group therapy sessions with the use of art and play therapy where indicated. Home, hospital and schoo visits were conducted to raise awareness of possible psychological sequelae and screen for those who had not come forward for help.

The program was run in the participants' home languages to enhance the effect. An interviewing form was used to collect demographic data and record the psychological symptoms pre and post intervention. Reviews of patient records as well as face-to-face interviews guided by a questionnaire were also used to collect the data. The group was assessed and analyzed according to levels of involvement as well as psychological morbidity.

An assessment at two years after the accident aims to determine how much psychological morbidity is still persisting following this program.

\section{RESULTS:}

Out of the 120 participants who were recruited to the intervention program at 6 weeks after the accident, only six had received psychiatric treatment. A the first session, 16 participants were assessed as moderately affected with symptoms requiring psychotherapy. Another 14 were assessed as severely affected with symptoms requiring psychotherapy and medication to return to productive lives. One required urgent hospital admission to treat a "catatonic" state. Some of those who did not require any intervention initially subsequently developed symptoms and joined the program for treatment.

At the completions of the intervention program, about 16 weeks after the accident, most of the participants had improved and were discharged from the program. Two of the participants were still under psychiatrist's treatment on medication and psychotherapy. Another 12 were still requiring psychotherapy, but all had improved from their initial assessment at presentation. The results of the two year assessment will be discussed at the conference with specific reference to the cultural context of the counseling program and its effects on the outcomes.

\section{CONCLUSION:}

Trauma counseling at a primary care level can improve outcomes in a group of individuals affected by a single identifiable stimulus if it is carefully planned and delivered in a culture sensitive approach.

\section{VULNERABILITY OF INDIVIDUALS IN A FAMILY SYSTEM TO DEVELOP A PSYCHIATRIC DISORDER}

Gerhard Grundling and Eugene Allers

Private Practice

\section{METHOD}

The first 100 Psychiatric Outpatients seen in a psychiatric practice and the first 100 Psychiatric Inpatients admitted to a psychiatric inpatient unit in 2003, with a diagnosis of Major Depression were selected for the study.

A genogram was drafted on all the patients at the first consultation. The position of the presenting patient in the family of origin and the interactions regarding the patient within the family system was evaluated to determine the vulnerabilities in family systems that are associated with psychiatric disorders.

Statistical analysis was performed on the data to determine the significance of the variables.

\section{ESULTS}

The results are discussed regarding the relevance of the variables. 


\section{WHAT DOES IT ÜBERHAUPT MEAN TO “INTEGRATE"?}

Jürgen Harms

Box 100, 7603 Lynedoch, Stellenbosch

\section{Background}

The congress theme implicates a problem. The term "integrating" suggests the importance of understanding complex systems.

Methods

Reflection upon the meaning of "integrating". Then a study of the literature of recent models of complex systems, and of integration in medicine, compared to an earlier model of integrated medicine. A critical appraisal of their value and limitations leads to an attempt to combine them in a model fit for human beings.

Results

Comparing the etymological origin of "integrating" with related concepts reveals that "integration" is about systems working properly as a whole.

Postmodern models of complex systems (Cilliers) provide detail about features of complex systems, but do not describe the essence of being-human (which concerns us most in psychiatry).

The German Academy for Integrated Medicine (founded in 1996) uses different circular models of semiotic interaction for different hierarchical system levels, emphasizing the "fitting" (or lack of it) in the doctor-patient system. These constructivist models do not arrive at the essential features of being-human

A model by the author (1984) derived from Heideggerian ontology, relates all systems of importance to humans to the entity of "being-human-in-relationships" and is therefore fully integrated, but lacks much of the valuable detail of the constructivist models. Heidegger explains the spirit of our age (control by controlling every detail) in his notion of "Gestell"; this explains also why models constructed from elementary constituents, but unconscious of the unity of being-human, are alienating our patients.

Conclusion

Available models are complementary and in combination can provide guidelines for integrated medical practice and education, provided we make a paradigm shift of consciousness from objects towards being.

\section{RESEARCH ISSUES IN SOUTH AFRICAN CHILD AND ADOLES- CENT PSYCHIATRY}

SM Hawkridge

Department of Psychiatry and Mental Health, University of Cape Town and Department of Psychiatry, University of Stellenbosch

WP Pienaar

Department of Psychiatry, University of Stellenbosch

Research in child and adolescent populations involves a constellation of ethical issues unique to these age groups. When research subjects, in addition to being legal minors, are psychiatrically ill, these issues become even more complex, and the rights of the child may be more vulnerable to infringement. This paper will provide a summary of the rights of the child as laid down in South African legislation and policy guidelines, followed by a description of the relevant stages of cognitive development of children and adolescents, and an overview of research in the field of child and adolescent psychiatry in South Africa during the past few decades. Some of the problem areas will then be highlighted. These will include:

- Informed consent/assent in children and adolescents

- Placebo treatment

- Relevance of research topics

- Under-researched areas

- The right of children and youth to appropriate research

The paper will conclude with suggestions as to how research protocols might be evaluated in the context of children's rights in South Africa.

\section{NEW RELIGIOUS MOVEMENTS AND PSYCHIATRY: THE GOOD NEWS}

Hitzeroth $\mathrm{VH}$

Fieldhead Hospital, Ouchthorpe Lane, Wakefield, WF1 3SP, UK

\section{BACKGROUND}

Alongside the world's great religions exist a significant number of religious cults, sects and new religious movements (NRM's). Over the last 50 years individuals, affected families, as well as the media have kept these groups under the spotlight. The general public perception is that these cults abduct innocent youngsters, brainwash them into submission using mind-contro techniques and enslave them in a world of hard labour and prostitution.
Some Psychiatrists have supported this view. Recent world events highlight the fact that a better understanding of these issues is critical.

\section{METHOD}

The presentation will guide the listener through the historical evidence as relayed by case reports and media coverage leading to more recent and scientific studies of NRM's. A short introduction on high profile cults will be given, including examples relevant to psychiatry. The question of "normal" religion will be addressed. The influence of the anti-cult movement will be highlighted. The effect of NRM's on children will be revisited. Lastly, the potential therapeutic effect of NRM's will be explained.

\section{RESULTS}

Early reports have reinforced the public perception that NRM's are indeed malignant organisations. No rigorous scientific study has supported this view. Although very few studies exist, those that have been published show a more benign body of evidence. Indeed, they reveal some surprising constructive and even positive views on the effect that some NRM's may be having on their members, their mental health and their children.

\section{CONCLUSION}

Initial media coverage and case reports were subjective and sensationalist Recent scientific studies reveal that some NRM's are stable, healthy communities where both adults and children thrive. The individuals' needs are often better met in these communities than in mainstream Western society. Indeed, there is some evidence that these children do better than their average Western counterpart. Some good news indeed!

\section{THE PREGNANT HEROIN ADDICT: INTEGRATING THEORY AND PRACTICE IN THE DEVELOPMENT AND PROVISION OF A SERVICE FOR THIS CLIENT GROUP}

Hitzeroth VH, Kramer L

Fieldhead Hospital, Ouchthorpe Lane, Wakefield. WF1 3SP, UK

\section{BACKGROUND}

To most clinicians working in the field of addiction psychiatry, the assessment and management of the pregnant heroin addict (PHA) remains a challenge. The difficulties encountered with this population include a lack of engagement with services, non-compliance with treatment, physical complications, numerous social problems and criminal concerns. This leads to inferior and interrupted care.

\section{METHOD}

This paper will integrate the latest research with my experience in developing and providing a service for pregnant heroin addicts at a county hospital in the UK. A review of recent literature will be presented. Particular emphasis will be placed on the multidisciplinary assessment process, selection of the intervention setting and the treatment options available to the prescribing psychiatrist (detoxification versus maintenance treatment). The difficulties with compliance and the maintenance of abstinence will be discussed Other topics that will be covered briefly include the effects of illicit and prescribed drugs on the unborn foetus, fertility in the drug addict, physical health in the PHA and the neonatal withdrawal state. An attempt will be made to integrate the research literature with the practicalities of providing a comprehensive service to the PHA, from first contact during pregnancy to discharge postpartum.

\section{RESULTS}

We were able to develop a multidisciplinary team that catered for this clien group. The team included a consultant psychiatrist, addictions community psychiatric nurse, midwife, neonatal ICU nurse, social worker, police and probation services. Our service had a wide and accessible referral base. Patients were engaged according to their needs. Good communication amongst the various professionals was possible and ensured safe practice.

\section{CONCLUSION}

Integrating theory and practice in the development and provision of a PHA service can provide safe treatment in demanding clinical situations. Patients feel satisfied with this accessible, flexible, multidisciplinary approach and professionals find it rewarding.

\section{AUTISM SPECTRUM DISORDER}

Erick Hollander

Professor, Department of Psychiatry, Director, Seaver and Greater NY Autism Center of Excellence, Clinical Psychopharmacology, and Compulsive, Impulsive and Anxiety Disorders Program, Mount Sinai School of Medicine

Autism is a neurodevelopmental disorder associated with substantial deficits in social interaction, speech, and communication, and the presence 
of compulsive and repetitive behaviors. Because autism is a developmental disorder, symptoms and behaviors change over time, and this process parallels changes in brain development. Autism is heterogeneous with respect to clinical symptoms and etiology, and varied presentations of the disorder may be the final common pathway of environmental factors and genetic fac tors. In addition to the core deficits, there are a number of impairments, such as mental retardation, seizures, self-injurious behaviors, and mood, eating, and sleep disturbances. A significant limitation in research of the neurobiology and treatment of autism has been the lack of attention to this heterogeneity, as well as changes in the diagnostic approaches to autism. A dimensional approach to the study of autism is valuable in linking key symptoms to the neurobiology and treatment of the disorder in a clinically meaningful way.

\section{RECENT ADVANCES AND MANAGEMENT IN TREATMENT RESISTANCE}

Eric Hollander

Professor, Department of Psychiatry, Director, Seaver and Greater NY Autism Center of Excellence, Clinical Psychopharmacology and Compulsive, Impulsive and Anxiety Disorders Program, Mount Sinai School of Medicine

Nonresponse to treatment in obsessivecompulsive disorder is common, associated with substantial impairment, and understudied. Little practical advice is available to clinicians on next-step treatment strategies for patients who have not responded well to 2 trials of selective serotonin reuptake inhibitors (SSRIs). Much knowledge about OCD comes from multicenter clinical trials, but for those working at specialty OCD centers, there is a constant struggle to find effective treatments for refractory patients which is clearly an unmet need. Many patients do not have a satisfactory

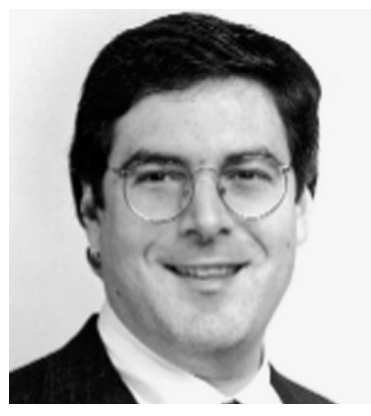
response to the standard treatments, and for these often comorbid and difficult-to-treat patients, few good data exist regarding appropriae and effective treatments. Should these patients be continued on their current medications for longer periods of time? Whould they be switched to other SSRIs or selective serotonin-norepinephrine reuptake inhibitors (SNRIs)? Would increasing the dose give a more robust response? Will augmenting with atypical neuroleptics or cognitive-behavioral therapy (CBT) be effective, or should a novel treatment approach be attempted, and are these strategies satisfactory and tolerable for most patients? Issues and strategies related to OCD treatment nonresponders will be considered.

\section{BIPOLAR MIXED STATES}

M. Leigh Janet

201 North Block, Sandton Mediclinic, Bryanston West

Summary: Bipolar mood disorder remains difficult to assess and diagnose accurately. A recent European survey of people living with bipolar disorde found a delay of 10 to 22 years before the diagnosis was made. $80 \%$ of psychologists, $80 \%$ of family practitioners and $50 \%$ of psychiatrists missed the diagnosis. Further studies show that $1.25 \%$ of patients diagnosed as having Unipolar depression 'convert' to bipolar disorder per annum. There are many reasons for this worrying state of affairs. In this paper, the author will briefly review the literature and discuss one of the most poorly assessed and diag nosed conditions in psychiatry, the bipolar mixed state.

\section{PROFILE OF ACUTE PSYCHIATRIC INPATIENTS TESTED FOR HIV — HELEN JOSEPH HOSPITAL, JOHANNESBURG}

Janse van Rensburg, ABR

Division of Psychiatry, Department of Neurosciences, Helen Joseph Hospital

\section{BACKGROUND}

Antiretroviral drugs (ARV's) were made available in certain hospitals in Gauteng in April 2004, of which Helen Joseph Hospital was one. A comprehensive pre-treatment assessment and briefing opportunity seems appropriate for prospective clients on the program, in view of the strict compliance and high level of motivation necessary to ensure favorable response and reduce the possibility of treatment resistance. A review was undertaken of HIV positive patients admitted to the psychiatric unit of Helen Joseph Hospital, to provide some indication of their ability and capacity in this regard.

\section{METHOD}

A review of the clinical data of HIV positive patients admitted to Ward 2, Helen Joseph Hospital over a one year period, was undertaken to establish the demographic, clinical, management and functional profile of this group.

\section{RESULTS}

During the initial 3 months of the study period, of a total number of 113 patients admitted to Ward 2, 22 patients' HIV status were tested, of which 8 were tested positive and 14 negative.

They presented on admission with symptoms ranging from elevated mood, psychosis, disorganized behavior, confusion, aggression and muteness. This group of patients on average stayed longer in hospital than the general group (22.6 days) and of those that tested positive, 2 were male and 6 female. All were diagnosed with either a mood disorder or psychosis due to general medical condition. On discharge, referrals were made to Community Psychiatric clinics, Helen Joseph outpatients, Tara and Sterkfontein Hospitals. In most case, due to their psychiatric diagnoses, these patients capacity to adhere to strict compliance has been significantly impaired and may even affect their access to ARV treatment.

\section{DISCUSSION}

This presentation provides a profile of psychiatric inpatients admitted to an acute unit of a general hospital and will consider some recommendations in view of this group's additional vulnerability.

\section{ADHD - USING THE ART OF FILM-MAKING AS AN EDUCA- TIONAL MEDIUM}

Shabeer Ahmed Jeeva

Child and Adult Psychiatrist, Credit Valley Hospital, 2200 Eglinton Ave. W. Mississauga, ON, Canada

A. Jain, Co-Author

There is a growing awareness in educational literature that visual strategies work best for ADHD patients. The art of film-making can be effectively utilized as a tool to help us navigate the emerging science of ADHD. Showing patients charts, graphs and electronic information has more appeal than auditory strategies (like an office based strategy). During this session, I will present movies that have a clear connection to both diagnosis and treatment of ADHD:

a) symptoms of impulsivity will be illustrated using clips from: Home Alone, Dennis the Menace and other key choices b) treatment strategies that illustrate the immature personality and growth will be using Mrs. Doubtfire and The Lion King. Understanding the personality profile that is a major component of long-term therapy a) dealing with attachment and trust issues b) using the " 3 year old with a booboo on their knee" to profile the treatment. Fostering the therapeutic alliance with the physician a) showing the movie Officer and a Gentlemen - attacking the vulnerability of Anti-Socia Personality Disorder b) pushing buttons with Good Will Hunting.

\section{TREATMENT OF ADULT ADHD CO-MORBIDITIES}

Shabeer Ahmed Jeeva

Child and Adult Psychiatrist, Credit Valley Hospital, 2200 Eglinton Ave. W., Mississauga, ON, Canada

A. Turgay, Co-Author

Adult ADHD is one of the most common psychiatric disorders with severe negative psychosocial impact for untreated patients. Over $60 \%$ of children with ADHD will still have serious symptoms in adulthood. Recent co-morbidity studies documented that most adult ADHD patients suffer from other co-morbid psychiatric disorders, the presence of which create a major challenge for psychiatrists and other physicians and also create treatment resistance. The most common co morbidities in adults with ADHD are majo depression, dysthymic disorder, bipolar disorder, personality disorders including borderline and antisocial personality disorder, substance use disorders; anxiety disorders including generalized anxiety disorder, OCD PTSD, organic brain syndrome, impulse control disorders and tic disorders. These patients not only suffer from the chronicity of their ADHD from early childhood but also experience serious stress and impaired quality of life associated with ADHD and other co-morbid disorders. Major depression and anxiety disorders impair these patients' already-limited attention and concentration functions, lower their job performance and worsen their interpersonal relationships. Physicians may have trouble determining an effective treatment approach for the patient with more than one disorder. This 
presentation will outline the findings of co-morbidity studies in adult ADHD and review the most effective treatment alternatives. Selective and/or combined use of effective medications in ADHD treatment for specific clusters of disorders commonly associated with ADHD will be outlined. The new generation long-acting psycho stimulants (ADDERAL-XR Concerta) and norepinephrine transport inhibitor atomoxetine will be compared to the old generation short-acting psycho stimulants (methylphenidate, dextroamphetamine). The use of tricyclic antidepressants (imipramine, desipramine), bupropione, mood stabilizers (valproate, carbamezapine, lithium) and atypical anti-psychotics (risperidone, olanzapine and quetiapine) will also be outlined. The integration and use of different medications to improve treatment response for clusters of co-morbidities (ADHD+ Major Depression; ADHD+ Anxiety Disorder, etc.) will be reviewed.

\section{NEEDS AND SERVICES AT WARD ONE, VALKENBERG HOSPITAL}

Dr J.A. Joska, Prof A.J. Flisher

Department of Psychiatry and Mental Health, University of Cape Town.

The mental health needs of patients entering the program at ward one, Valkenberg Hospital, are not routinely measured. Their presenting problems are frequently complicated by basic and social needs, which impact on recovery and re-integration into the community. The Camberwell Assessment of Need is a valid and reliable instrument used to measure the mental health needs of psychiatric patients. In this study, this instrument was used with some modifications to assess the needs of patients on admission to ward one. At discharge, these needs were explored to measure the extent to which services and interventions were useful in meeting those needs. Where not, questions aimed at elucidating impediments to care were asked.

All 100 patients completing the program agreed to participate. The average number of total needs on admission was 8.60, which included an average of 6.44 unmet needs. Psychiatric needs were the most commonly reported, with a need in the area of "depression" being declared in 97 patients. Help received prior to admission was scant, and patients had high expectations of ward one.

Help received from ward one was highest in areas of psychiatric needs, with $89.69 \%$ of patients receiving moderate or high help in the area of depression. More than two-thirds of patients reported receiving low help in basic areas such as, accommodation, self care, and sexual expression. The services most often regarded as useful were organised group activities and therapies. Analysis revealed that there were no differences in unmet needs between patients in a range of psycho-social and psychiatric variables. Regression analysis suggests that younger age, lower level of education and borderline personality confer a greater risk of unmet needs on admission and discharge.

The routine use of a needs assessment instrument is recommended as an aid to guide clinicians. Attention needs to be given to basic and social needs, such as accommodation, daily activities and company, prior to admission to hospital. Where these needs persist, the active involvement of a social worker and occupational therapist is suggested. The high numbers of unme needs in domains other than psychiatric problems requires the input of the multidisciplinary team.

\section{UNANSWERED QUESTIONS IN THE ADEQUATE TREATMENT OF DEPRESSION}

Moderator: Dr André F Joubert, Lundbeck Institute, Copenhagen Expert: Prof Tony Hale, University of Kent, UK

There are several treatment decisions regarding the adequate treatment of depression that do not have a sufficient evidence base. Therefore we rely on expert opinions and common sense. Also, some of the emerging evidence for decisions is changing.

The discussion will focus on the 7 treatment principles:

Diagnosis, Choice of mediation, Dose, Side effects, Duration of treatment, Discontinuation and follow-up, and Psychotherapeutic interventions.

We will start by review the of guidelines and evidence regarding the options available, hoping to answer some of these questions:

- Subtyping and severity

Subtyping of depression is becoming an integral part of diagnosis.

Which subtypes of depression have an impact on treatment decision?
How does this impact the choice of medication?

- Treatment duration - 1st episode patients, multiple episode and elderly patients

- What is the current evidence and are changes happening in the guidelines?

- Tapering up doses — to reduce side effects, reduce onset anxiety symptoms

Is tapering up of doses to be recommended?

Is there evidence to support this strategy?

- When should non-response be evaluated?

How long after starting an antidepressant can "response" be evaluated?

When should the dose be increased?

When is switching medication recommended?

- What is the first decision in the case of non-response and partia response?

Most will first optimise the dose of the antidepressant. Is this correct?

When would we try augmentation and which would we use first, dose, duration?

- Psychotherapy

What specifically is the role of CBT? Should this be recommended for as many patients as the literature is currently suggesting? Is that practical? What is the true value of supportive (psycho-)therapy?

\section{UNANSWERED QUESTIONS IN TREATMENT RESISTANT DEPRESSION}

Moderator: Dr André F Joubert, Lundbeck Institute, Copenhagen Expert: Prof Sidney Kennedy, University of Toronto, Canada

There are several decisions regarding Treatment Resistant Depression (TRD) that do not have a sufficient evidence base. Therefore we rely on expert opinions and common sense. Also, some of the emerging evidence for decisions is changing.

We will start by proposing a definition of TRD and follow that with a review of guidelines and evidence regarding the options available, hoping to answer some of these questions:

- The role of the new generation antipsychotics in TRD

The CANMAT guidelines suggest the use of the new generation antipsychotics only as an augmentation with the second-line

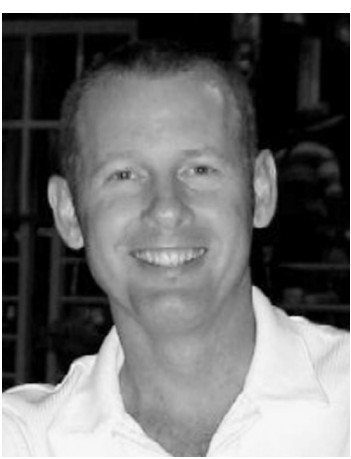
antidepressant used. With the considerable new data, are we seeing this guideline changing so that new generation antipsychotics will be recommended with the first-line antidepressant - along with lithium and T3? Is there evidence for the use of mood stabilisers and lamotrigine?

- Switching antidepressants

When switching from the first antidepressant to the second antidepressan - due to non-response. There are conflicting data. Should there be a switch of class of antidepressant used?

- Combination treatment with antidepressants

Many psychiatrists use combinations of antidepressants (SSRI + SNRI

SSRI + Mirtazapine et al.) There are few data to support these practices. What are the principles involved in combining antidepressants?

Combinations are often used in patients who are not "treatment resistant", and within 3 weeks of starting the first antidepressant.

\section{ARE MENTALLY ILL PEOPLE DANGEROUS?}

Sean Z Kaliski

Associate Professor, Department of Psychiatry, Universisty of Cape Town, and Forensic Psychiatry Unit, Valkenberg Hospital, Cape Town

Until recently mental health professionals insisted that mentally ill individuals did not pose any greater risk of acting aggressively than the genera population. Deinstitutionalisation of chronic patients from psychiatric hospitals proceeded partly on this assumption. This was surprising given the longstanding, and widespread practice of involuntary admission of psychiatric patients that were deemed 'dangerous'. In fact, the essential problem always was in defining the term 'dangerousness', and then reams of research displayed convincingly that it was not possible to predict accurately enough who would be violent, and when this might occur. When epidemiologica studies in the 1990's began to confirm that those with serious psychiatric disorders indeed do behave more violently than the general population two important shifts in approach occurred. Firstly, clinical assessment was 
replaced with actuarial methods, and secondly 'prediction of dangerousness' was abandoned in favour of risk assessment. Currently actuarial instruments that measure the degree of risk rely on computations of static and dynamic risk factors. The former, which include demographic, dispositional and historic factors, cannot be changed, whereas the latter, consisting of clinical mental state and alcohol/substance abuse, are amenable to clinical intervention (that is, risk management). In short, most mentally ill individuals are not dangerous, but a significant minority is, and this lecture will discuss their systematic assessment

\section{THE CHILD CUSTODY CIRCUS}

\section{Sean Z Kaliski}

Associate Professor, Department of Psychiatry, University of Cape Town, and Forensic Psychiatry Unit, Valkenberg Hospital, Cape Town

South Africa lacks an accreditation system for psycholegal experts, and consequently many clinicians are conducting psycholegal assessments without supervision or peer review. The profound consequences of poor standardisation of these practices are occurring dramatically in divorce and child custody assessments. Although legislation does not provide criteria for these assessments the general rule is that the 'best interests of the child' must be served. Despite its good intentions this term suffers from vagueness. Two systems are currently available to divorcing couples (who are usually urged to settle via mediation). Either they can be assessed by the Office of the Family Advocate, where a family advocate and family counsellor (usually a social worker) conduct interviews and make recommendations to the court, or private practitioners can be retained to assess and recommend on custody, access and other issues that concern the couple. The latter situation usually arises when the couple are at odds, have financial resources, and the plaintiff wishes to limit or exclude the defendant's access, or uses this as a tactic, perhaps, for extracting greater concessions (such as higher maintenance payment). Often a group of experts, including up to 4 clinical psychologists, social worker and child psychiatrist, is retained. Each member of the team conducts extensive interviews, and at least one will insist on spending extended periods in the divorcing couples household in order to observe nat uralistically the interactions between the parents and the children. Ultimately lengthy reports, often containing verbatim interactions (which may be unethical), are produced that may actually result in vague recommendations. A common result is that the father (usually) is subjected to supervised access on alternative weekends. The supervisor not uncommonly is a young university student who is paid a high hourly rate. Often the total account for these assessments is more than R100 000. Several cases will be presented in which this procedure has occurred. In conclusion standardised criteria for these assessments will be proposed, which will include peer review and a consideration of the child's wishes.

\section{THE APPROPRIATENES OF CERTIFICATION OF PATIENTS TO PSYCHIATRIC HOSPITALS}

V.N. Khanyile

Sterkfontein Hospital and Department of Psychiatry, University of the Witwatersrand

In South Africa, Section 9 and 12 of the Mental Health Act No. 18 of 1973 as amended, provide standards and procedures for the involuntary commitment of mentally ill person to mental institutions, or care and rehabilitation centres. In day to day practice with real families, real patients and real crises clinicians are faces with a number of challenges. One such challenge is the appropriatness of certification of patients to psychiatric hospitals. It is not uncommon in practice to find patients that clinicians may regard as inappropriately certified to psychiatric hospital for varied reasons.

Over a period of years, there has been a shift in commitment criteria towards dangerousness as possibly the only justification for involuntary commitment of mentally ill patients to psychiatric hospitals, with a strong emphasis on the rights of individuals. The contibutiory factor amongst others, was the vagueness of commitment criteria, which may have lead to inappropriate certification or patients to psychaitric hospitals. In practice clinicians have to balance between treatment needs of a patient an their rights to ensure that mentally ill patients receive adequate management.

\section{HIV/AIDS PSYCHOSOCIAL RESPONSES AND ETHICAL DILEM- MAS}

Fred Kigozi

Consultant Psychiatrist/Medical Director, Butabika National Referra Mental Hospital, Uganda.

The Global HIV/AIDS epidemic is one of the greatest challenges facing our generation. Epidemiological findings and projections indicate that the AIDS crisis is continuing to deepen in Africa with over two-thirds of all new infections and people now living with HIV/AIDS in the World being found in Africa especially Sub-saharan Africa.

Similarly, over $80 \%$ of the AIDS related deaths have occurred in Africa yet the region has only $22 \%$ of the world's population. The magnitude of this epidemic and its effects on individual's, families and the

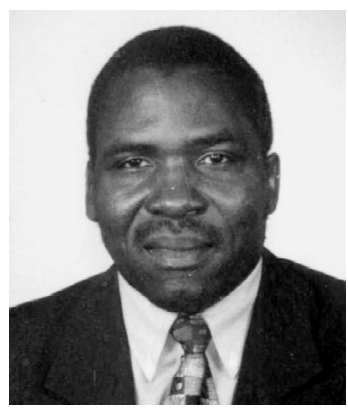
larger communities has equally challenged ethical precepts from the earlies days of the pandemic and it continues to pose agonizing dilemmas in all countries, rich and poor.

AIDS patients major battles revolve, in particular, around issues of professional confidentiality, ensuring access to the available therapies and testing new ones in an ethical manner.

These challenges in the HIV/AIDS pandemic will be discussed with particular emphasis on Sub-saharan Africa.

\section{SEX AND PSYCHIATRY}

B Levinson

I will review the Fathers of psychiatry and discuss their ground breaking involvement in the world of Sexology. I will explore how we have relentlessly progressed away from the time honoured world of 'talking therapy' with its core of hearing what the patient says, to the brave new world of neuropharmacology.

I will examine aspects of listening and demonstrate dynamically how to listen The session will be as interactive as possible.

\section{VIOLENCE AND ABUSE IN PSYCHIATRIC IN-PATIENT INSTITU- TIONS: A SOUTH AFRICAN PERSPECTIVE}

Marilyn Lucas

Associate Professor and Head of Psychology, Faculty of Arts, Monash, South Africa

John Weinkove

Consultant Psychiatrist, Rand West Care Centre, Millsite Complex, Krugersdorp

Dean Stevenson

Senior Psychiatrist, Werribee Mercy Mental Health Program, Footscray, Victoria, Australia

Background: Institutionalisation of psychiatric patients was a prevalen treatment approach in the apartheid era of South Africa. Allegations of violence and abuse towards patients frequently arose during this time. The post-apartheid Department of Health prioritised improvements in menta health care by recommending, inter alia, deinstitutionalisation and reintegration of patients into the community. Ten years later, these interventions have proved difficult to institute and many patients are still hospitalised The present study investigated whether currently hospitalised patients continued to experienced violence and abuse.

Method: This was an exploratory naturalistic study in which both qualitative and quantitative data was collected by means of a questionnaire.

Results: Of the 127 who completed with questionnaire, $52.8 \% \quad(n=67)$ reported that they had been physically abused; sexual abuse was reported by $18.9 \%(n=24)$ of the patients and experiencing verbal abuse from hospital staff was reported by $37 \%(n=47)$ of patients. The main perpetrators were other patients, although violence by staff was reported.

Discussion: Reasons for the tardiness of implementation of desinstitutionalisation and the prevalence of ongoing violence and abuse in psychiatric hospitals are complex. Factors inherited from the pre-democratic system coupled with increased urban violence and financial constraints appear to be some of the major causes of ongoing dependency upon hospitalisation of mental health care users. 


\section{PUBLIC HEALTH SECTOR EXPENDITURE FOR MENTAL HEALTH - A BASELINE STUDY FOR SOUTH AFRICA}

E N Madela-Mntla

National Department of Health

\section{BACKGROUND:}

Mental health services in South Africa, like in most countries, have historically occupied a low priority position. Despite its prioritization at nationa level in 1998, sentiments have been expressed about this trend not filtering through to service level. This despite the WHO's recommendation that $10 \%$ of the total health budget be spent on mental health. In an attempt to determine South Africa's expenditure in this regard, the Department commissioned out a study, completed in 2003, with the objective to determine public health sector expenditure on mental health as a baseline for future planning and lobbying for improved mental health services.

\section{METHOD:}

A semi-structured questionnaire was administered through interviews with provincial mental health coordinators.

\section{RESULTS:}

Overall, the information obtained helped in establishing trends on the bases of which recommendations were made. Key difficulties related to the avail ability and reliability of information and financial data at provincial and lower levels. Several Provinces followed an integrated budget approach, which made it difficult to ring fence expenditure per programme. In some Provinces, information was decentralised to facility level, with no feedback information for the provincial office apart from the amount allocated to the facility. Where some data was available, comparable figures were mostly difficult to obtain because of lack of standardization in information systems CONCLUSIONS:

Even though data were not accurate, the study confirmed that there is gross underspending in the public health sector on mental health. In some provinces, this is way below the WHO's recommendation, with negative growth trends, considering inflation. The expenditure is even lower for contracted mental health care, and we know this has a direct correlation with the quality of services. One of the biggest challenges facing the sector is the need for standardized information management systems without which service planning will continue to be a hit-and-miss.

\section{HIV IN SOUTH AFRICA: DEPRESSION AND CD4 COUNT}

M Y H Moosa, F Y Jeenah

Department of Psychiatry, Faculty of Health Sciences, University of the Witwatersrand

Background: Although estimates of the prevalence of depressive symptoms in people with HIV infection have varied widely in the literature, it has become increasingly clear that they occur frequently. The aim of the study was to determine the occurrence of depression amongst HIV positive patients and its relationship to the CD4 count.

Method: Forty-one patients of 18 years of age or more were recruited from the HIV outpatient clinic. All the subjects completed the 21-item Beck's depression inventory (BDI) and their CD4 counts were determined. Patients who had a score of $\geq 10$ on the BDI were considered positive for a depressive disorder.

Results: The study sample was divided into two groups: those with a CD count $<200$ and those with a count of $\geq 200$. There was no significant difference between the groups with respect to age, gender, marital status, employment status and highest level of education $(\mathrm{p}>0.05)$. There was no significant difference in the BDI scores within the groups $(p>0.05) .56 \%$ $(n=23)$ of the patients had a BDI score of $\geq 10$, indicating that they had significant symptoms of depression, with no correlation between CD4 count and BDI scores ( $\mathrm{r} 2=0.0062 ; \mathrm{p}>0.05)$. A significant finding was that in the depressed subgroup, $77 \%(n=15)$ had a CD4 count of $\geq 200$ as compared to $23 \%(n=8)$ with a count of $<200(p<0.05)$, suggesting that the diagnosis of depression is probably not a misinterpretation of physical symptoms due to HIV infection per se.

Conclusion: The findings of this study suggest that depression is common among patients with HIV infection irrespective of their CD4 counts. The BDI is a quick and effective way to screen for depression in HIV-infected patients and should be followed up by a structured interview to confirm the diagnosis.

\section{CLINICAL STRATEGIES IN DEALING WITH TREATMENT RESISTANT SCHIZOPHRENIA}

Piet Oosthuizen, Dana Niehaus, Liezl Koen

Department of Psychiatry, Faculty of Health Sciences, University of Stellenbosch

Although treatment resistance in schizophrenia may be difficult to define, it is generally accepted as failure to respond to two different antispychotics given in adequate doses over an adequate trial period. Clozapine is widely accepted as the gold standard for treating these patients. However, only a portion of patients resistant to standard treatment regimes will respond to clozapine, leaving clinicians with a large body of patients who remain severely impaired on many levels.

In this presentation, we will discuss different aspects of treatment resistant schizophrenia

a) Defining the problem

b) Evidence based best practice - the current options

c) Novel strategies for overcoming treatment resistance

d) Amisulpride as augmentation to clozapine - local experience.

\section{BUPRENORPHINE/NALOXONE MAINTENANCE IN OFFICE PRACTICE: 18 MONTHS AND 170 PATIENTS AFTER THE} AMERICAN RELEASE

Ted Parran Jr, Chris Adelman

CWRU School of Medicine, 10900 Euclid Ave, Cleveland OH, USA

Background: Opioid dependence is at epidemic proportions in many industrialized societies. Traditional detoxification and abstinence based treatment has severe limitations when applied to heroin addiction, and in many countries legal restrictions regarding methadone maintenance severely limits access to treatment.

Methods: Case-series of 170 patients induced on buprenorphine-naloxone for office based maintenance in general psychiatry or primary care physician practices

Results: The demographic, heroin or other opioid use histories, psychiatric dual-diagnosis are presented of the first 170 patients induced on buprenorphine-naloxone maintenance in Cleveland Ohio, USA. The withdrawal symptoms, side-effects, treatment retention, stabilizing dose, compliance with counseling, and urine toxicology screen results over a period of up to 18 months follow-up are also presented.

Conclusions: Strengths and limitations of buprenorphine-naloxone as an adjunct to a comprehensive addiction treatment program for opioid are discussed. Implications of this treatment for other practices, other cultural groups and nationalities are considered.

INTEGRATION OF PHARMACOTHERAPY FOR OPIOID DEPENDENCE INTO GENERAL PSYCHIATRIC PRACTICE NALTREXONE, METHADONE AND BUPRENORPHINE/NALOXONE

Ted Parran

CWRU School of Medicine, 10900 Euclid Ave, Cleveland OH, USA

\section{Background}

Opioids and nicotine are drugs of abuse that use specific defined receptor systems. Consequently they are the current drugs of abuse that show promise for maintenance with either antagonist or agonist agents. Fortunately several options currently exist which, if used appropriately can augment an abstinence-based addiction recovery program. Integrating the science of opioid pharmacotherapy into treatment counseling is a challenge to psychiatric physicians and treatment program leaders.

Learning Objectives:

Participants will -

1. Review the data regarding the use of antagonists and agonists in opioid dependence

2. Identify challenges to the use of pharmacotherapy in addiction treatment

3. Develop strategies to resolve challenges and balance the need to accommodate innovation of pharmacotherapy and tradition of 12-step counseling

Workshop outline:

Large group exercise: opioid dependence - long-term recovery issues. Small group exercise: the challenges for recovery.

Large group exercise: managing challenges.

Small group exercise: integrating pharmacotherapy - nuts and bolts.

Large group exercise: summary and recommendations. 


\section{BIODANZA}

Pauw A, Van Zyl L

\section{Introduction}

The use of movement as a form of therapeutic intervention evolved in the 1940 - 1950's. Movement therapies have a holistic aim where cognitive, emotional and physical aspects are all taken into account.

\section{Origins of Biodanza}

Rolando Toro, a professor in Medical anthropology at the University of Santiago, Chile, created Biodanza in the 1960's. It is currently practiced in schools worldwide i.e.: Uruguay, Chile, Argentina, Spain, France, Germany, Japan, Italy and South Africa.

\section{Aims of Biodanza}

Biodanza focuses on the conservation of life. It uses the body as a link to recover a connection between emotion, movement and relational identify. The group provides a safe space for participants to develop different aspects of themselves such as vitality, affectivity, sensuality, creativity and transcendence. The combination of music and movement is carefully chosen and no formal dance steps are required.

Biodanza facilitators undergo a training lasting between two and half to three years which includes theoretical work, presentation of a thesis and personal growth through a Biodanza process under the supervision of an experienced teacher.

Further research

Research investigating the influence of Biodanza on people using various psychological (regulation of emotion, health, personal psychology) Physiological (skin response and blood pressure) and immunological (immunoglobin A) variables have been conduted since 19998 at the Leipzig University under the supervision of Dr Marcus Stück. Research is also being conducted at the Biocentric Foundation and University of Buenos Aires.

\section{OUR AFRICAN UNDERSTANDING OF INDIVIDUALISM AND COMMUNITARIANISM}

\section{Willie Pienaar}

Associate Professor, Faculty of Health Sciences, University of Stellenbosch Principal Psychiatrist, Associated Psychiatric Hospitals, PAWC, Stikland Hospital

Background: We treat our patients as individuals, asking of them to make their own choices and decisions, respecting their autonomy and right to selfdetermination. But they (our patients) are part of a family, a specific culture, and society as a whole. The therapist should not neglect the role of the family, the culture, and the community in patient decision-making. The lives of individuals cannot be fulfilled and completed if that life is not 'connected' to others. Is it not because our 'connectedness' that we can enjoy a full and complete life?

Moral deliberation: In this presentation the moral good of personal autonomy, individual rights and respect for freedom of the individual are weighed against the common good of society, communitarian principles and cultural norms. Further discussion will focus on self-actualization of a person within his/her community. The obligations, duties and interdependence of the individual and the community will be reviewed. Conclusions based on this deliberation will be put forward to better our therapist-patient interactions.

\section{HEALTHY AGEING AND THE PREVENTION OF DEMENTIA}

Felix Potocnik, Susan van Rensburg, Christianne Bouwens

Departments of Psychiatry, Clinical Pathology and Internal Medicine, University of Stellenbosch

Background: In 2000 our planet Earth had passed the 6 billion mark for the total human population which is set to peak at 9 billion around 2070 before declining to 8.4 billion at the end of the century. Notably our current proportion of elderly amounting to $10 \%$ will reach $34 \%$ by 2100 .

Though mankinds' estimated life-span is 120 years. Non-communicable diseases that cause our premature deaths are listed as cardiovascular $(53 \%)$, cancer $(17 \%)$, respiratory disease $(14 \%)$, and the dementias $(5-10 \%)$. These diseases in turn are greatly influenced by our state of nutrition (under nutrition, malnutrition, obesity), substance abuse (alcohol, cigarettes, drugs) and medical control. Longstanding disability prior to death is an increasingly important social and national health problem and we thus distinguish between life expectancy (longevity) and healthy life expectancy ( the number of years that we live without disability
Review: The World Health Organisation surveyed healthy life expectancy in 191 countries (including South Africa) around the world in 1999. While certain individuals or population subgroups have more healthy life expectancy years and lower death rates than other groups, simple measures can successfully be implemented to improve healthy life expectancy in emerging population groups.

The unprecedented rise in patient numbers with dementia could be followed by declining numbers in years to come as the long-term effects of healthier living habits exert themselves.

Alzheimer's disease and Vascular Dementia in the elderly account for between $90-95 \%$ of all dementias, and there is a strong association between them and the risk factors for cardiovascular disease.

Results: Indications are that the following either slow down, or possibly even help prevent these dementias:

1)genetic profile, 2) hormone replacement therapy (oestrogen), 3) low dose anti-inflammatories, 4) vitamins C and E, 5) red wine, 6) intellectual stimulation, and 7) especially, the control of cardiovascular risk factors. These include hypertension, diabetes, hyperlipidaemia and smoking, which are associated with endothelial stress and inflammation, and the control of hyperhomocysteinaemia.

\section{INDIGENOUS PLANTS AND METHODS USED BY TRADITIONAI AFRICAN HEALERS FOR TREATING PSYCHIATRIC PATIENTS IN THE SOUTPANSBERG AREA( Research was done in 1998)}

Ramovha Muvhango Rachel, Limpopo College of Nursing, Thohoyandou Campus

This study was under taken in order to establish the medicinal plants used by indigenous traditional healers, so that the cause of resistive extra pyramidal side effects can be understood.

Research question: Why do mentally ill patients treated by indidenous healers present with side effects similar to those produced by psychotropic drugs used in hospitals?

Method: The study is a qualitative, contextual, exploratary since it was interested in the holistic nature of the African traditional healing interpreted within the healers context and also to unravel meanings inherent in the situation. It was ethno- medical since it was to find out the traditional indigenous plants used in the treatment and methods used to treat mental illness. Only specialist healers in mental illness in the Soutpansberg area were selected to give information.

Results: A list of names of indigenous plants used as medicines was compiled and such medicinal plants were identified by their botanical names. Treatment methods employed were also identified. Also recorded was the part of the plant used as treatment.

Conclusion: The study found that in traditional medicine the cause of similarity of such side effect could not be established since the plants used as treatments could not be tested for toxicity or their chemical compositions. From this study it is hoped that the department of health and the community health professionals will establish good relations that will aid in the acceptance of each other's advice in mental health care. It is hoped that this study will serve as a starting point for ethno-bothanists and chemists for further research.

\section{SYMPTOM PATTERN \& ASSOCIATED PSYCHIATRIC DISOR- DERS IN SUBJECTS WITH POSSIBLE \& CONFIRMED 22Q11 DELETIONAL SYNDROME}

J.L. Roos*, H.W. Pretorius*, M. Karayiorgou**

* Department of Psychiatry University of Pretoria, South Africa

** Human Neurogenetic Laboratory, The Rockefeller University, New York

It has been shown that patients with a hemizygous deletion of the q11 band of their chromosome 27 [otherwise diagnosed as 22q11 Deletion Syndrome, $22 q 11 \mathrm{DS}]$ are at very high risk for serious psychiatric illness. A previous study reported a $2 \%$ frequency rate of the 22q11 deletion syndrome in adult Afrikaner Schizophrenic patients.[1] Studies of symptom patterns and associated psychiatric disorders in schizophrenic patients with 22q11 DS may help to determine the relationship of a 22 q11 DS subtype to the heterogeneous entity known as schizophrenia.

\section{METHOD:}

Patients with possible 22q11 DS were identified in a ongoing genetic study for schizophrenia, according to screening criteria proposed by Basset et al. [2] This genetic study of schizophrenia at the University of Pretoria, Department of Psychiatry and the Human Neurogenetics Laboratory of The Rockefeller University has been ongoing since 1997.[3] The following data will be reported on in the affected subjects: Psychiatric and associated dis- 
orders, age of onset, cognitive deficit, early deviant behaviours and longitudinal course of illness.

\section{RESULTS:}

8 Subjects with 22 q11 DS were identified according to clinical screening criteria and in 2 of the subjects a hemizygous deletion on chromosome $22 q 11$ were confirmed with FISH analysis. Schizophrenia and schizoaffective disorder was reported in $50 \%$ of subjects respectively. Psychiatric symptomatology of most case included: Paranoid delusions, auditory hallucinations, speech disturbance and/or bizarre and aggressive behaviour Those subjects with earlier age of onset of illness had more early deviant behaviour reported. OCD featured prominently in those cases of 22q11 DS who were confirmed by FISH analysis. Most subjects had a chronic deteriorating course of illness.

\section{DISCUSSION:}

The number of 22q11 DS subjects are small and no definite conclusions can be made. Specific symptom patterns do seem to emerge, including bizarre and aggressive behaviour and OCD comorbidity. It seems to be a chronic deteriorating form of illness.

CONCLUSION:

22q11 DS subtype schizophrenia is currently an under-recognized entity By collecting larger samples of this population, the symptom pattern and associated psychiatric disorders will become more distinct. This information coupled with structural and functional brain abnormalities as well as clinical molecular epidemiology may lead to the ethiopathogeneses of a subtype of schizophrenia.

\section{DURATION OF ANTIDEPRESSANT TREATMENT: HOW LONG IS LONG ENOUGH? HOW LONG IS TOO LONG}

Steven P Roose

Professor of Clinical Psychiatry, College of Physicians and Surgeons, Columbia University

The optimal duration of acute phase antidepressant treatment is uncertain..$^{1,2}$ There are divergent goals when considering trial duration. One goal is to ensure that patients have sufficient opportunity to remit by providing sufficient treatment exposure that may require a long trial duration. The second goal is to minimize exposure to infective treatment which prolongs suffering, and may exacerbate morbidity by contributing to hoplessness and subsequent treatment nonadherence or refusal. To minimize exposure to infection treatment, it necessary to determine the shortest trial duration that will detect patients unlikely to remit.

The adoption of remission as the treatment aim

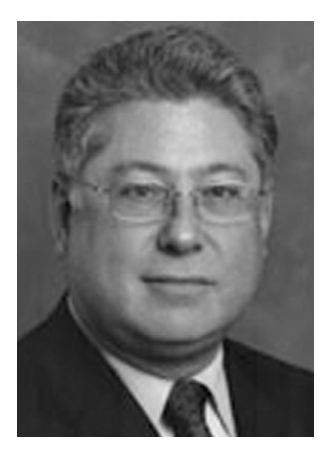
has deepened the divergence between these

goals. More time is needed for patients to achieve remission compared to response, leading to longer trial duration.17,18 However, while it is generally estimated that $50-70 \%$ of patients respond during an acute phase antidepressant trial, only $20-45 \%$ achieve remission. 19,20 Therefore, the majority of patients have prolonged exposure to treatment that does not result in remission.

Analysis of large databases from RCT's of antidepressant treatment using signal detection theory provides critical data that allows the clinician to make evidence based decisions on when to switch or continue a patient's antidepressant treatment. The goals of minimizing exposure to ineffective treatment and yet maximizing remission rates cannot be fulfilled by the use of fixed treatment duration in antidepressant trials and requires the adoption of a innovative new approach, duration adaptive designs.

1. Nierenberg AA, Farabaugh AH, Alpert JE, et al. Timing of onset of antidepressant response with fluoxetine treatment. Am J Psychiatry 2000;157:1423-1428.

Reynold CF 3rd, Frank E, Kupfer DJ. Treatment outcome in recurrent major depression: a post hoc comparison of elderly ("young old") and midlife patients. Am J Psychiatry 1996;153:1288-1292.

\section{A COMPARISON STUDY OF EARLY NON-PSYCHOTIC DEVIANT BEHAVIOUR IN THE FIRST TEN YEARS OF LIFE, IN AFRIKANER PATIENTS WITH SCHIZOPHRENIA, SCHIZO- AFFECTIVE DISORDER AND BIPOLAR DISORDER}

Martin Scholtz, Melissa Janse van Rensburg, J. Louw Roos Department of Psychiatry, University of Pretoria

Objective:

To determine whether the high incidence of early non-psychotic deviant behaviour, as found in previous studies in patients with schizophrenia and schizo-affective disorder, is unique to these illnesses, or whether it also occurs in bipolar disorder. It was suggested previously that the early nonpsychotic deviant behaviour could be used as an endophenotypic marker in genetic studies of schizophrenia and schizo-affective disorder.

\section{Methods:}

Patients with schizophrenia, schizo-affective disorder and bipolar disorder were interviewed by means of a structured questionnaire probing for early deviant childhood behaviour starting before the age of 10 years. Information from close family members was also obtained where possible. Seven areas of possible deviance were probed into: social dysfunction, unprovoked aggression, extreme anxiety, chronic sadness, extreme odd behaviours, attentional impairment and learning difficulties. Demographic data included: age, gender, marital status and years of formal education. The following illness characteristics were also recorded: age of onset of illness and suicide attempts.

Results:

Patients interviewed included: schizophrenia $(n=79)$; schizo-affective disor$\operatorname{der}(\mathrm{n}=42)$; and bipolar disorder $(\mathrm{n}=74)$. Early deviant behaviour was more prominent in schizophrenia (65\%) and schizo-affective disorder $(60 \%)$, than in the bipolar group $(21,6 \%)$. The different types of early deviant behaviour will be compared for the different diagnostic categories. Bipolar patients had the highest incidence of suicide attempts.

\section{Conclusion:}

These findings suggest that early deviant behaviour may be used as a possible endophenotypic marker in schizophrenia and schizo-affective disorder but not in bipolar disorder.

\section{TREATMENT, TREATMENT ISSUES, AND PREVENTION OF PTSD IN WOMEN: AN UPDATE}

\section{Soraya Seedat}

MRC Unit on Anxiety and Stress Disorders, Department of Psychiatry, Stellenbosch University, Tygerberg, W Cape

The higher lifetime risk of posttraumatic stress disorder (PTSD) in women may be attributable to factors other than trauma type, such as sensitization of stress hormone systems in response to early adverse experience, inherent neuroendocrine factors, subjective interpretation of the event, and peritraumatic dissociation. Women arguably experience a greater symptom burden, longer course of illness, and have worse quality of life outcomes than men. This presentation will provide an overview of (i) the psychobiological alterations in women with PTSD and (ii) the efficacy of pharmacologic and psychosocial treatment options. Randomized controlled studies conducted in large samples of women with chronic PTSD indicate that: (i) selective serotonin reuptake inhibitors (SSRIs) have efficacy on all three symptom clusters of PTSD and should be used as first-line, and (ii) cognitive-behaviora strategies (e.g. prolonged exposure treatment and cognitive processing) are a gold standard treatment as they are effective in sexually and non-sexually assaulted women. Studies also suggest that female gender may be associated with better response rates to pharmacotherapy. The shifting hormonal milieu may influence responsiveness to pharmacotherapy and this needs to be borne in mind when treating women. Recent studies highligting the potential usefulness of antiadrenergic agents and preventive CBT treatments in managing acute trauma reactions and preventing the emergence of PTSD, will be discussed.

\section{FROM NEURAL NETWORKS TO CLINICAL PRACTICE}

Spitzer, M

Medical Director, Professor and Chairman (Head of Department) of the newly established Psychiatric Hospital at the University of Ulm, Germany

Neural network models of cognitive functioning have been proposed a hundred years ago. Then, neurons had just been described and synapses had not been given their proper name, although they have been postulated. In 1943 , a seminal paper by a mathematician and a physiologist opened up the new field of mathematical modeling of neuronal function. In the fifties, such models were eagerly developed and built, but by the end of the 1960s, severe limitations brought the filed to a stanstil. Only when new learning algorithms were designed in the 1980s, and upon papers by a physicist published in respectable journals, neural network research had a comeback - and it is here to stay! I will present exaples from neural network research that make clear the relevance of the models. I will argue that only through modeling we gain the deep understanding of the neuronal underpinnings of higher cognitive functioning that we need for a foundation of clinical psychiatry. 


\section{OPENING KEYNOTE PRESENTATION: THE ART AND SCIENCE OF PSYCHIATRY}

Spitzer, M

Medical Director, Professor and Chairman (Head of Department) of the newly established Psychiatric Hospital at the University of Ulm, Germany

Present day psychiatry is applied neuroscience, in particular, applied cognitive neuroscience. For the first time in the history of our field we gain a genuine undersatanding of general aspects of the workings of the human brain and can apply it for the benefits of our patients.

\section{Examples}

Range from neuronal growth to neuroplasticity and neuromodulation, and their relevance for the treatment of depression and schizophrenia. The aspect of application, however, emphasizes that there is more to the foundations of psychiatry than brain scanning and genetics. Only by careful listening and observing, we will be able to use our general knowledge for the benefit of the patients and for the benefit of future psychiatry. I will try to illustrate these points with examples from my own work as well as recent examples taken from the general research literature.

\section{THE FUTURE OF PHARMACOTHERAPY FOR ANXIETY DIS ORDERS}

Dan J. Stein

MRC Unit on Anxiety Disorders, University of Stellenbosch, PO Box 19063, Tygerberg 7505

Advances in psychiatric nosology and the introduction of modern antidepressant agents has led to significant advances in the treatment of anxiety disorders. Nevertheless, these agents are not without disadvantages, and a significant proportion of patients with anxiety conditions fail to respond to first-line agents. Furthermore, these agents act on the same limited number of neurotransmitter pathways as did the early antidepressants. Developments in the cognitive-affective neuroscience of anxiety indicate, however, that the future will see the introduction of agents with novel mechanisms of action and perhaps particularly useful clinical niches. This presentation outlines some of these developments, and new molecular targets for the treatment of anxiety disorders, including cortisol release factor, glutamate, and neurotrophic factors.

\section{NEUROPSYCHOLOGICAL DEFICITS PRE AND POST ELECTRO CONVULSIVE THERAPY (ECT) THRICE A WEEK: A REPORT OF FOUR CASES}

Ugash Subramaney

Senior Consultant, Community Health Services, Department of Psychiatry,

University of the Witwatersrand

Yusuf Moosa

Senior consultant, Johannesburg Hospital, Department of Psychiatry, University of the Witwatersrand

\section{Background}

Cognitive deficits are common in Major Depression. Many patients also report cognitive side effects during a course of ECT. This study reports on neuropsychological findings after a course of ECT in 4 patients with Major Depression who received ECT 3 times a week.

\section{Methodology}

Four patients who were admitted to the Johannesburg Hospital for treatment of Depression, and referred for ECT, were included in this study. Severity of depression was assessed using the Hamilton Rating Scale for Depression (HAMD), as well as the Montgomery Asberg Rating Scale for depression (MADRS). This was done at baseline, after 6 treatments, at the end of the course of ECT and at 3 months.

Cognition was assessed using the trail making $\mathrm{A}+\mathrm{B}$, the complex figure of Rey, the Rey Auditory Verbal Learning tests (RAVLT) and two components of the SAWAIS. This was done at the same time as the rating scales.

ECT was given according to hospital guidelines using bilateral, bitemporal placement, and standard anaesthetic procedure

Results

Three patients were over 60 years of age. One was 41 years.

Severity of depression at baseline as rated by both scales was typically high, except for the HAMD of 1 patient.

Cognitive changes in keeping with depression were seen in the patients pre ECT, with improvements post ECT.

There were distinctly low scores on the TMT and AVLT post ECT.

\section{Conclusions}

Depression causes distinct cognitive disturbances. It is highly likely that the TMT and AVLT are sensitive to the cognitive effects of ECT. The potential of these tests as indicators of depression is also apparent, with significant improvements being seen pre and post ECT.

\section{Limitations}

Small sample size. All patients were female, all but one $>60$ years old Cognitive effects of normal aging must be borne in mind when interpreting the results.

\section{PREVALENCE OF AND RISK FACTORS FOR TARDIVE DYSKI- NESIA IN A XHOSA POPULATION IN THE EASTERN CAPE}

Dave Swingler ${ }^{1,3}$, Betty D. Patterson, ${ }^{2}$ Sandi Willows ${ }^{3}$

${ }^{1}$ Rhodes University, Grahamstown

${ }^{2}$ College of Pharmacy, North Dakota State University, Fargo, ND, USA

${ }^{3}$ Fort England Hospital, Grahamstown

Background: Despite prolonged antipsychotic drug use, the prevalence of tardive dyskinesia (TD) in a Xhosa population has not been evaluated. This study undertook to determine such prevalence, and to identify potential factors that may influence the risk of TD.

Methods: 102 subjects who had been on continuous antipsychotic drug therapy for at least 6 months were screened for abnormal movements using the AIMS rating scale. Demographic data, current and past antipsychotic drug use, concurrent use of other psychotropic medications, psychiatric diagnosis, smoking history, and dietary factors were gathered from patient interviews and chart reviews. Total current and cumulative antipsychotic drug doses were converted to chlorpromazine equivalents for comparative purposes.

Results: Most patients received injectable depot medication: only $16.5 \%$ took oral medication alone. $28.4 \%$ of subjects met criteria for TD. Years of documented treatment (12.8 vs. 8.8) and total chlorpromazine dose equivalents (1042.6 gms vs. $720.5 \mathrm{gms}$ ) were significantly associated with a positive AIMS rating. Patients on concurrent antidepressant therapy were less likely to have a positive AIMS rating. There were no statistically significant effects of age, sex, or diagnosis on the prevalence although a trend suggested an increased risk over age 60 . Subjects with higher total consumption of foods containing antioxidants had lower rates of TD, but only onion consumption was significantly associated with a reduced prevalence. A history of smoking was not associated with altered risk, but a trend showed reduced prevalence of TD with increased years of smoking.

Conclusions: TD in this population is more prevalent than previously believed, but is comparable to that reported in similar studies of other populations. Total cumulative antipsychotic dose and duration of treatment are significant risk factors. Antioxidants may provide some protection against development of TD. Further study of the role of concurrent medications and dietary factors is indicated.

\section{EATING DISORDERS: ADDICTIVE DISORDERS?}

Christopher Paul Szabo

Professor and Clinical Head, Division of Psychiatry, Faculty of Health Sciences, University of the Witwatersrand, Johannesburg

The relationship between eating disorders and substance abuse is well established in terms of co-morbidity. The nature of that relationship is however not precisely understood, nor is there agreement. The conceptualisation of eating disorders as addictive disorders is appealing as there appear to be common elements. The question is whether this understanding has either validity or utility. 


\section{ETHICAL CHALLENGES AND DILEMMAS OF RESEARCH IN THIRD WORLD COUNTRIES}

Godfrey B. Tangwa

Associate Professor of Philosophy, University of Yaounde 1, Yaounde, Cameroon

Third world countries, particularly in the continent of Africa, today find themselves in the unenviable situation of combining a high burden of sundry diseases with acute resource poverty, illiteracy and ignorance. This situation poses many challenges and dilemmas. For one thing, medical research to find appropriate and affordable remedies to the diseases most afflicting third world country populations is an incontrovertible necessity, in fact, a rational imperative, although the ethical pitfalls of doing research among desperately ill and impoverished people, anywhere at any time, must be kept in mind. For another, the adequate resources for such research simply are not available in third world countries. The industrialized developed countries, with a lighter burden of disease by comparison, do have abundant resources for medical research. But developed world medical research in the developing world raises serious ethical questions and needs to scale very high ethical hurdles. In this presentation, I will attempt to reflect on the challenges, the dilemmas and the ethical imperatives of medical research, particularly in the present context of Africa.

\section{THE INTERFACE BETWEEN NEUROLOGY AND PSYCHIATRY WITH SPECIFIC FOCUS ON SOMATOFORM DISSOCIATIVE DISORDERS}

Michael Trimble

Consultant Physician, Department of Psychological Medicine, National Hospital for Neurology and Neurosurgery, London

The first part of the talk will deal with the history of hysteria with particular reference to post traumatic hysteria the importance of such conditions as Railway Spine will be emphasised. A brief over view of the works of Janet, Charcot and Freud will be mentioned. The presentation will then go on to look at Shell Shock and the War Neuroses taking the story of hysteria, now rechristened Somatoform Disorder and its variants into the late 20th Century.

Essentially the lecture will by this poin have emphasised the way that concept regarding these clinical presentations have swung back and forth between psychologi-

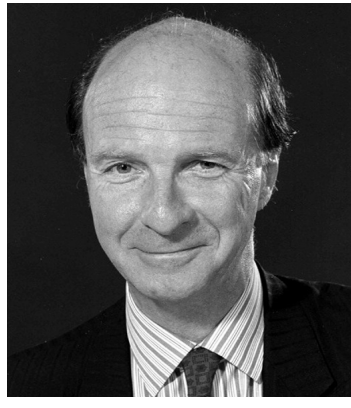

cal and organic theories, and the contemporary views which still seem ambivalent on this matter.

The development of the concept of Somatisation Disorder will then be discussed. This involves an understanding of the origin of Briquet's Hysteria and the rediscovery of these chronic often neurologically disabled patients in the latter half of the 20th Century as the pinnacle of the hysteria concept which still baffles clinicians.

One disorder which has been viewed traditionally as entirely neurological is atypical dystonia. This disorder now rechristened psychogenic dystonia will be presented and its relationship to neurological disease and somatoform disorder discussed.

\section{PREVALENCE AND CORRELATES OF DEPRESSION AND ANXI- ETY IN DOCTORS AND TEACHERS}

Van der Bijl, H., Oosthuizen, P.

Department of Psychiatry, Faculty of Health Sciences, University of Stellenbosch

\section{Background:}

Both doctors and teachers in South Africa are exposed to high levels of stress at work. There have been many reports in the media about job dissatisfaction among these professionals, however we could not find any scientific publications evaluating the prevalence of anxiety and depression in these groups in South Africa.

The aim of this study was to evaluate the prevalence of symptoms of anxiety and depression in doctors and teachers in the northern suburbs of Cape Town and to assess correllations with job dissatisfation and perceptions about being overworked.

Method:

We surveyed 200 doctors and 200 teachers in the northern suburbs of Cape Town with a self-rating questionnaire that included the Hospital Depression and Anxiety scale as well as questions on job satisfaction and perceptions on workload.

\section{Results:}

The response rate was higher among teachers $(88.5 \%)$ than doctors $(51.9 \%)$ We found high levels of anxiety and depression in both groups, although it was statistically significantly higher in teachers than in doctors. Univariate analysis of variance showed that being a teacher, being dissatisfied with your job as well as the perception of being overworked were all significant predictors of symptoms of anxiety and depression.

\section{Discussion:}

Although symptoms of depression and anxiety are common among teachers and doctors in the northern suburbs of Cape Town, teachers seem to be affected more than doctors. The very high prevalence of depression and anxiety among teachers in more affluent areas may be indicative of a similar or even worse situation in poor areas.

\section{INGRID JONKER: A PSYCHOLOGICAL ANALYSIS}

L.M. van der Merwe

In an effort to learn more about the intricate "art of being human", the life and work of Ingrid Jonker (1933 - 1965) are subjected to Psychological analysis. Careful scrutiny of her career aims at gaining a deeper understanding of mankind in general and gifted, creative people in particular.

Throughout the years there has been a mutually beneficial interaction between literature and psychology. This analysis has hopefully made a small contribution to the history of that interaction.

Art is not to be reduced to psychopathological phenomena. Ingrid Jonker was selected because of her important position in South African literature, her influence on other artists, the circumstances characterizing her life and the era in which she lived.

The analysis is aimed at a better understanding of a person not present in an immediate, face-to-face situation. An "analysis in absentia" is, however, cast in the same mould as other psychotherapeutic efforts also based on empathic understanding of one's fellow man.

The psychologist enters the domain of art in his capacity as psychotherapist. No attempt is made at criticizing art or expressing an appreciation. The analysis is aimed only at gaining a deeper understanding of Ingrid Jonker's life, at getting to know the person behind the literary works. It leads to the synthesis of hitherto unrelated ideas concerning her life and work, and to explanations of unexplained aspects of her behaviour. It does not reduce her to a diagnosis : "... And above all do not make me a thing; a thing with one face like water held in the hands would spill me, otherwise kill me".

Her capacity to maintain partial objectivity, even when intensely involved in a situation, is analogous to the work of a psychotherapist. Like any othe discipline, psychology is subject to limitation and cannot furnish all responses to the riddle of life.

\section{THE STRANGE WORLD WE LIVE IN, AND THE NATURE OF THE} HUMAN SUBJECT

Vasi van Devente

Department of Psychology, University of South Africa

\section{Objective}

Twentieth century physics and philosophy saw a drastic review of the nature of physical reality and the nature of the observer. The aim of this paper is to expose practitioners of psychiatry to contemporary ideas about the nature of the human subject against the background of the world exposed by 20th century physics and philosophy, and to indicate the relevance of these understandings for psychiatric practice.

\section{Method}

The paper provides a brief overview of those developments in physics and philosophy that resulted in the movement from first to second to third order cybernetics. First order cybernetics brought the understanding that the effects of behaviour plays back into the causes of behaviour. Second order cybernetics accommodates the fact that humans are observers of the systems in which they themselves are actors. But in doing so second order cybernet- 
ics presupposes the existence of the subject. Therefore, the task of third order cybernetics is to explore a world that includes not only the observing subject but also the subject observing. The present paper explores the selfreferential subject as a possible solution to third order cybernetics. The arguments can be quite complex, but I avoid these complexities by utilising examples from psychiatry, and simple diagrams, to demonstrate the basic principles of self-referential systems, and to indicate the implications of these ideas for psychiatric practice.

\section{Results}

The paper offers at least two interesting, and counter-intuitive, conclusions, namely (a) that the world in which humans find themselves is not a world that contains them, but rather a world that appears as the limit of the human being, and (b) that the human subject occupies a strange place in its world, by being neither present in nor absent from this world.

\section{Conclusion}

The implication of these conclusions is that the world appears as the solution of a symmetric inter-subjective relationship. Psychosis, therefore, is the inability to resolve and maintain the symmetries of inter-personal relationships.

\section{ART IN PSYCHIATRY: APPENDIX OR BRAIN STEM?}

CW van Staden

Objective: To consider various places of art in psychiatry and argue for a balanced approach to science and art in psychiatry.

Methods: The concepts related to 'art' (e.g. reasoning, humanities, ethics, aesthetics, values, skills, attitudes, subjectivity, meanings, etc.) are examined through conceptual analysis for their potential relevance in psychiatric science, practice, education and research. Practical examples are considered for the desirability, the necessity, and the sufficiency of these concepts in psychiatric practice.

Findings: About a century ago, the psychiatrist and philosopher, Karl Jaspers, emphasised the importance in psychiatry of science as well as art; causes as well as meanings/reasons; explanation as well as understanding; objectivity as well as subjectivity. Today, after considerable advances in psychiatric science and the huge benefits it brought for patients, art in psychiatry may appear less important and at best, a nice-to-have, as if art in psychiatry is merely about the finishing touches. On the other hand, psychiatrists are confronted with the contemporary demands of idealism and post-modernism, striving that we relinquish empirical science, causes, explanations and objectivity.

A balanced approach, instead, calls for the legitimate place of science and of art in psychiatry, where legitimacy of each is determined by their necessity, desirability and sufficiency in psychiatric theory, practice, education or research.

Conclusion: Within a balanced approach to science and art in psychiatry, the advances in psychiatric science drives growing sophistication of art at the centre of a person-centred practice in psychiatry.

\section{MEDICAL STUDENTS ON WHAT "SOFT SKILLS” ARE ABOUT, BEFORE AND AFTER CURRICULUM REFORM}

CW van Staden; PM Joubert; A-M Bergh; GE Pickworth; WJ Schurink; RR du Preez; JL Roos; C Krüger; SV Grey; BG Lindeque

Background: Curriculum reform had aimed inter alia to give more emphasis to "soft skills" that include professional interpersonal and social skills, communication skills, as well as professional and ethical attitudes. This presentation reports on the ways in which medical students conceptualised "soft skill" in a study among two groups of medical students before and after curriculum reform at the University of Pretoria.

Method: Qualitative methods were used to compare descriptively the conceptualisation of soft skills by the final year medical students of the traditional curriculum with that of the reformed curriculum. Sampling was purposive-theoretical by which 42 students from the traditional curriculum and 49 from the reformed curriculum were sampled. Data were collected by means of 7 focus groups, 16 individual interviews, and 23 essays (autobiographical sketches).

Findings: Both groups of students revealed conceptualisations of soft skills that were similar in kind, denoting thematically the doctor-patient relationship; relationships with other professionals; being a good listener; explaining to patients; using good communication skills; establishing rapport with patients from different cultural backgrounds; having a certain correct atti- tude; being really interested in patients' well being; having empathy; managing difficult situations, and being ethical and professional. However, the traditional curriculum students offered fewer examples and experiences that exemplified their soft skills. Students of the reformed curriculum gave rich accounts of their conceptualisation in terms of their own experiences and practical examples of how soft skills had been or could be used, particularly in difficult interpersonal situations. Moreover, they came up with helpful ways of dealing with difficult situations, which were additional to the ways offered by the traditional curriculum students.

Conclusion: The reformed curriculum students were more prepared in soft skills through educational and training efforts, which may explain their awareness and apparent adeptness at applying soft skills to demands of difficult clinical situations.

\section{ATTENTION DEFICIT HYPERACTIVITY DISORDER (ADHD) - MEDICAL MANAGEMENT. METHYLPHENIDATE (RITALIN) OR ATOMOXETINE (STRATTERA)?}

André Venter

Academic Head, Department of Paediatrics and Child Health, University of the Free State, Bloemfontein

Results of studies such as the MTA study have clearly indicated that medica management of ADHD should form an integral part of the holistic approach to these disorders. Soon, in South Africa, a new medication will become available called Strattera (Atomoxetine). Although there has been much hype in the popular press regarding this non-stimulant treatment of ADHD, it is imperative that all professionals who work in the field understand what could be expected from this medication, when it is indicated and how it differs from Methylphenidate.

\section{Methylphenidate (Ritalin)}

Mechanism of action. Methylphenidate is a dopamine transporter inhibitor and therefore has an effect on the dopamine pathway for attention. It is a mild CNS stimulant with more prominent effects on mental than on motor activities and it may also lead to stimulation of the reticular activation centre.

Pharmacokinetics. After oral administration, Methylphenidate is rapidly and almost completely absorbed and owing to extensive first-pass metabolism, it's systemic availability is only $30 \%$ of the original dose. Ingestion with food accelerates absorption but has no effect on the amount absorbed Plasma peak concentrations are reached on average one to two hours after administration, but peak plasma concentrations vary markedly between patients. Methylphenidate is eliminated from the plasma with a mean halflife of two hours. Almost 78-97\% of the dose is excreted in the urine within 48 to 96 hours.

Drug interactions. Ritalin should be used with caution in patients treated with blood pressure agents and MOA inhibitors. It may inhibit the metabolism of anti-coagulants, some anti-convulsants and tri-cyclic anti-depressants. Alcohol may exacerbate the adverse CNS effects.

Indications. Methylphenidate is indicated for Attention Deficit Disorder. It is indicated as part of a comprehensive treatment programme, which typically includes psychological, educational and social measures and is aimed at stabilizing children with a behavioural syndrome characterized by moderate to severe distractibility, short attention span, hyperactivity, emotional ability and impulsivity.

Complications of long term use. As Methylphenidate has been used for more than 60 years, it is now known that there are no major long-term complications of this medication.

Contra-indications. Contra-indications include hypersensitivity to Methylphenidate, anxiety, tension, agitation, hyperthyroidism, cardiac arrhythmia, severe angina pectoris, glaucoma, diagnosis of motor tics or tics in a sibling and a family history of Tourette 's syndrome. It has to be mentioned that most of these are relative contra-indications.

Precautions. Ritalin has not been registered for children under the age of 6 years, since safety and efficacy in this age group has not been established Ritalin may exacerbate symptoms of behavioural disturbance and disorder in psychotic children. Chronic abuse of Ritalin can lead to marked tolerance and psychological dependence with varying degrees of abnormal behaviour.

Caution is called for in emotionally unstable patients. It must be noted that clinical data indicate that children given Ritalin are not more likely to abuse drugs as adolescents or adults.

Ritalin should be used with caution in patients with epilepsy. If seizure frequency increases, Ritalin should be discontinued.

Moderate reduced weight gain and slight growth retardation have been reported with long-term use, although a cause relationship has not been confirmed.

Blood pressure should be monitored in appropriate intervals in all patients 
taking Methylphenidate, especially those with hypertension. Studies to establish safe use of Methylphenidate in pregnant women have not been conducted and it is not known if the active substance of Ritalin passes into breast milk.

Paediatric use. The safety and efficacy of Methylphenidate in paediatric patients less than six years have not been established.

Side-effects and adverse reactions. Common side effects: Nervousness and insomnia, which occur in the beginning of treatment, can usually be controlled by reducing the dose or eliminating the afternoon or evening dose. Decreased appetite is also common but transient. Abdominal pain, nausea and vomiting are common, usually occur at the beginning of treatment and may be alleviated by concomitant food intake. Tachycardia, palpitations, changes in blood pressure and heart rate may be noted, a rash, pruritis, urticaria, fever and scalp hair loss as well as arthralgia.

Dosage. Currently in South Africa there are three formulations available.

(i) Ritalin $10 \mathrm{mg}$ - short acting.

(ii) Ritalin SR tablets, the strength $20 \mathrm{mg}$. These tablets have a duration of about 8 hours and may be used when a prolonged effect is desired. SR tablets must be swallowed whole and should not be crushed or chewed and should be taken after meals, preferably after a substantial breakfast.

(iii) Ritalin LA capsules are for oral administration once daily in the morning and is available in 20,30 and $40 \mathrm{mg}$ formulations. A $10 \mathrm{mg}$ may soon also be available. It may be administered with or without food, should be swallowed whole, but could be administered by sprinkling the contents over a small amount of food.

(iv) Concerta: Concerta is not yet available in South Africa, but is also a long acting Methylphenidate with a progressive increased available dosage during the day.

\section{Advantages of Methylphenidate}

1. Methylphenidate long acting and slow release tablets offer a once daily dose.

2. Side-effects are generally transient or could be controlled by decreasing the dose.

3. It is effective for all the symptoms of Attention Deficit Disorder.

4. Improvement with this medication can be quite dramatic.

5. Its effects on appetite and growth appear to be minimal and it is a well researched drug with a great deal of experience.

6. It is relatively inexpensive.

\section{Disadvantages}

1. Some of the side-effects of Methylphenidate may be unacceptable.

2. It has abuse potential.

3. Because of its high scheduling, prescription is a problem.

\section{Atomoxetine (Strattera)}

Mechanism of action. Atomoxetine is a highly specific nor-epinephrine transporter inhibiter and therefore has an effect on the alternative pathway for attention as opposed to Methylphenidate, which is Dopaminergic. In fact, Atomoxetine has very little Dopaminergic effects.

Pharmacokinetics. Atomoxetine is well absorbed after oral administration and is minimally affected by food. Although its half life is about 5 hours, its clinical efficacy is much longer than this. Atomoxetine structure is unrelated to any substance of abuse. A once daily dose would be adequate, but the dosage is related to weight and effects are only visible after four to six weeks of medication. Atomoxetine is excreted primarily in the urine $(<80 \%$ of the dose).

Drug interactions. No significant drug interactions have been identified including the use of Methylphenidate, with very few exceptions.

Indications. Atomoxetine will be registered for the treatment of ADHD. The effectiveness of Atomoxetine in the treatment of ADHD has been established in four randomized double-blind placebo controlled studies of paediatric patients in ages 6 to 18. It appears to improve all three main symptom complexes of ADHD.

Complications of long term use. Has not been systematically evaluated. Contra-indications

1. Hypersensitivity. There may be some patients who are hypersensitive to Atomoxetine.

2. Patients using Monoamine Oxidase Inhibitors.

3. Patients with narrow-angle Glaucoma.

4. Growth. In the randomized controlled studies, children who received Atomoxetine, were more likely to loose at least $3.5 \%$ of there body weight than the placebo groups. In some of these groups high doses of Atomoxetine were used. There did not appear to be any significant differences as far as height was concerned. Whether final adult height or weight is affected by the treatment of Atomoxetine, is unknown.

Precautions. Because Atomoxetine could have a theoretical affect on blood pressure and heart rate, it should be used with caution in patients with hypertension, tachycardia, cardiovascular or cerebrovascular disease. Carcinogenesis, mutogenesis and impairment of fertility: Atomoxetine appeared to have no effect of any of the above.

Paediatric use. The safety and efficacy of Atomoxetine in Paediatric Patients less than 6 years have not been established. The efficacy of Atomoxetine beyond 9 weeks and the safety beyond 1 year of treatment have not been systemically evaluated.

Side-effects and adverse reactions. Reasons for discontinuation of treatment due to adverse events in child and adolescent clinical trials included

1. Aggression

2. Irritability

3. Somnolence

4. Vomiting

Only two subjects in the population of 427 had significant side-effects. Other side-effects would include upper abdominal pain, decreased appetite, headaches, but it should be borne in mind that in the majority of cases similar numbers were identified in the placebo groups.

Dosage. Strattera should be initiated at a total daily dose of approximately $0.5 \mathrm{mg} / \mathrm{kg}$ and increased after a minimum of three days to a target daily dose of approximately $1.2 \mathrm{mg} / \mathrm{kg}$. It is probably not useful to increase it beyond $1.4 \mathrm{mg} / \mathrm{kg}$. In children and adolescents over $70 \mathrm{~kg}$, total daily dose of $40 \mathrm{mg}$ should be used initially and increased after a minimum of three days to a target daily dose of $80 \mathrm{mg}$. Atomoxetine are supplied in 10, 18, 25, 40 and 60 milligram strengths.

\section{Advantages}

2. Atomoxetine is a one-daily dose.

3. It has no abuse potential

4. It does not cause dysphoria on discontinuation and has no pleasurable or euphoric states.

5. It appears to be effective for all the symptoms of Attention Defici Disorder.

6. It appears to be useful for children with poor self-esteem, behavioural problems and improving psycho-social wellbeing.

7. It is a "subtle" medication with no dramatic side-effects.

8. Its effects on appetite and growth appear to be minimal

9. Lower scheduling may facilitate prescription.

\section{Disadvantages}

1. Atomoxetine is a new medication. It has been prescribed in the United States for 1 year now and long-term effects and side-effects have not been systematically evaluated.

2. Because of its subtle effects, it may be a disappointing treatment for those requiring dramatic effects.

3. In some children side effects may become a problem. Effects are only noticeable after 4-6 weeks.

4. Cost may be prohibitive.

\section{A COMPREHENSIVE GUIDE TO THE TREATMENT OF ADULTS WITH ADHD}

WJC Verbeeck

Vincent van Gogh Institute, Postbus 5, 5800 AA Venray, The Netherlands

There is compelling evidence that the syndrome of Attention Defici Hyperactivity disorder (ADHD) persists from childhood into adulthood, reaching prevalence rates that are higher as compared to schizophrenia .Still, this highly heritable condition is vastly under-recognised.

Despite the growing consensus related to the validity of this clinically heterogeneous disorder, the search for an endo-phenotype remains shrouded in controversial and often inconsistent findings.

The variegated symtomatology can be attributed to the existence of severa subtypes, the severity of the disorder and the presence of co-morbid conditions.Because adults with ADHD have often learned to compensate for hyperactivity and impulsivity, the symptomatic continuity tends to gravitate towards deficits in executive functioning.

This presentation will focus on a four pronged treatment approach to ameliorate the functional impairment of this dysexecutive syndrome.The multimodal strategy includes psychopharmacotherapy, psycho education ,psychotherapy and the use of support groups.

Practical guidelines to combat co-morbid disorders, treatment resistence and poor compliance will be addressed. 


\section{TREATMENT OF INSOMNIA: STASIS OF THE ART?}

GC Verster

PO Box 232, Somerset West, 7129

\section{Background}

Insomnia is a very prevalent problem in the adult population and is associated with numerous comorbid medical and psychiatric conditions. Untreated insomnia also leads to marked impairment in occupational and social functioning. This paper examines and compares the advances in the treatment of insomnia over the past two decades.

Methods

A MEDLINE search was done to investigate current trends and new developments in the treatment of insomnia. Available literature published during the past two decades was used and compared to new developments.

Results:

The mainstay of pharmacological treatment of insomnia was the short-acting hypnotic benzodiazepines. Development of new hypnotics has been ongoing since the introduction of the so-called non-benzodiazepine hypnotics. Compounds such as indiplon and eszopiclone are the latest in this class. Advantages over the older hypnotics have been proven, but many of the caveats regarding long-term use and abuse potential persist. The efficacy of these drugs in severe insomnia is also limited.

Antidepressants with sedative properties are also widely used in the treatment of insomnia, and because of their perceived lack of abuse potential, often in chronic patients. Concerns about safety, especially relating to daytime sedation are being raised in the current literature.

The non-pharmacological management remains an important part of the treatment, and recently a number of randomized controlled studies have been published to evaluate the efficacy of these methods.

\section{Conclusion:}

The treatment of insomnia has benefited from the introduction of new compounds with improved safety profiles. Behavioural techniques have been utilized for a number of years and studies are continuing, but major advances have been few. Numerous deficiencies in the treatment of insomnia persist, especially in the treatment of resistant and long-term insomnia.

\section{ARE PRISONERS VULNERABLE RESEARCH PARTICIPANTS?}

\section{Merryll Vorster}

Professor, Division of Psychiatry, Department of Neurosciences, University of the Witwatersrand

Psychiatrists are accustomed to dealing with vulnerable patients as part of their daily work. Can they be of assistance in tackling the problem of prisoners participating in research activities especially in South Africa where prisoners may be of the opinion that it is their right to participate?

\section{PSYCHIATRIC DISORDERS IN THE GYM}

Merryll Vorster

Professor, Division of Psychiatry, Department of Neurosciences, University of the Witwatersrand

Substance abuse is not usually associated with individuals who appear healthy and who exercise frequently but is this a misconception?

This paper will deal with the problem of abuse of anabolic steroids and stimulants containing ephedrine like substance ("fat burners") and their psychiatric sequelae.

ADVERTORIAL

\title{
Cipralex: Effects on anxiety symptoms in Major Depressive Disorder
}

\author{
Bruce Lydiard \\ Medical University of South Carolina, 171 Ashley Avenue \#623, Charleston, SC 29425 USA
}

Background: Anxiety is a common symptom in depressed patients, associated with poor outcome and increased severity of the disorder. An optimal antidepressant drug should therefore also alleviate anxiety symptoms. Cipralex (escitalopram) is the S-enantiomer of the SSRI antidepressant citalopram.

Objective and methods: Recently, two randomized (one fixed and one flexible dose), double blind, eight-week, placebocontrolled, multi-center studies of Cipralex (10-20 mg/day) and citalopram (20-40 mg/day) were conducted in patients with major depressive disorder (DSM-IV). Both studies were of common design and had common patient entry criteria. Anxiety symptoms were measured by the Hamilton Depression Rating Scale (HAMD) anxiety subscale and the Hamilton Anxiety Scale (HAMA).

\section{Results:}

- Cipralex 10-20mg daily significantly improves symptoms of anxiety and depression.
- Cipralex has a fast onset of action in reducing anxiety symptoms of depression.

- Cipralex $10-20 \mathrm{mg}$ is associated with a low overall incidence of activation adverse evetns.

\section{Conclusions:}

These data clearly demonstrate that Cipralex is efficacious in the treatment of anxiety symptoms in depression.

For further information please contact:

Elaine Milne at Lundbeck SA on Tel: 0116991600

References:

1. Hyttel J, Bogeso KP, Perregaard J, Sanchez C.The pharmacological effect of citalopram resides in the (S)-(+)-enantiomer. J Neural Transm Gen Sect. 1992;88:157-60

2. Lepola UM, Wade AG, Leinonen EV, Koponen HJ, Frazer J, Sjodin I, Penttinen JT, Pedersen T, Lehto HJ. A controlled, prospective, 1-year trial of citalopram in the treatment of panic disorder. J Clin Psychiatry. 1998;59:528-34 